\title{
Comparison between Hydrogen and Syngas Fuels in an Integrated Micro Gas Turbine/Solar Field with Storage
}

\author{
Maria Cristina Cameretti, Alessandro Cappiello, Roberta De Robbio* $*$ and Raffaele Tuccillo \\ Department of Industrial Engineering, University of Naples Federico II, 80125 Naples, Italy; \\ mc.cameretti@unina.it (M.C.C.); alessandro.cappiello@unina.it (A.C.); raffaele.tuccillo@unina.it (R.T.) \\ * Correspondence: roberta.derobbio@unina.it
}

Received: 9 June 2020; Accepted: 3 September 2020; Published: 12 September 2020

\begin{abstract}
In recent years, the use of alternative fuels in thermal engine power plants has gained more and more attention, becoming of paramount importance to overcome the use of fuels from fossil sources and to reduce polluting emissions. The present work deals with the analysis of the response to two different gas fuels-i.e., hydrogen and a syngas from agriculture product-of a $30 \mathrm{~kW}$ micro gas turbine integrated with a solar field. The solar field included a thermal storage system to partially cover loading requests during night hours, reducing fuel demand. Additionally, a Heat Recovery Unit was included in the plant considered and the whole plant was simulated by Thermoflex ${ }^{\circledR}$ code. Thermodynamics analysis was performed on hour-to-hour basis, for a given day as well as for 12 months; subsequently, an evaluation of cogeneration efficiency as well as energy saving was made. The results are compared against plant performance achieved with conventional natural gas fueling. After analyzing the performance of the plant through a thermodynamic analysis, the study was complemented with CFD simulations of the combustor, to evaluate the combustion development and pollutant emissions formation, particularly of $\mathrm{NO}_{\mathrm{x}}$, with the two fuels considered using Ansys-Fluent code, and a comparison was made.
\end{abstract}

Keywords: agricultural product; cogeneration; exergetic analysis; hydrogen; micro gas turbine; syngas

\section{Introduction}

Micro Gas Turbines (MGT) represent a promising solution for distributed cogeneration due to important energy saving and reduction in pollutant emissions which characterize this type of power plant. Furthermore, we are witnessing a great variety of gas turbine-based hybrid power plants that combine two or more power generating devices and make use of the synergism to generate maximum power and heat recovery, thus offering high efficiencies. In this regard, for small-scale, distributed energy application, hybrid systems based on the integration between solar field and gas turbine (GT) technologies are recognized as a very interesting solution [1-6].

In addition, the flexibility of gas turbines offers the possibility to use alternative fuels that can further reduce the carbon footprint and energy demand. Particularly, two type of fuels are receiving growing attention-i.e., syngas and hydrogen - since they can be produced from wind or solar power and from any hydrocarbon-based feedstock gasification or pyrolysis of biomasses [7-12]. In particular, the syngas, consisting of a mixture of methane, carbon monoxide, hydrogen and a significant amount of inert gases, such as carbon dioxide and nitrogen, with percentages of each species being dependent on the gasification process used for its production, shows a lower LHV with respect to the natural gas. Consequently, the fuel change imposes a substantial increase in the fuel mass flow rate in order to meet the same turbine inlet temperature (TIT), leading to an off-design operation of the whole 
system and to a change in the reacting mixing quality in the combustion chamber, which in turn requires a trade-off between combustion efficiency, pollutant formation and overall system efficiency [9]. Additionally, another characteristic issue related with use of syngas fuel in MGT combustors is a poor combustion completion.

On the other hand, the use of hydrogen fuel offers several appealing features, such as a high LHV and a carbon-free composition, although some other critical aspects are associated with its use in MGT combustors, namely the increase in $\mathrm{NO}_{\mathrm{X}}$ production due to the higher flame temperature and the risk of flashback [10].

The use of these new fuels has been investigated by several researchers, who tried to address the abovementioned issues. Concerning syngas fuel, Abagnale et al. [7] investigated the performance of a $30 \mathrm{~kW}$ MGT annular combustor when fueled with two type of syngas and found that syngas from biomass gasification, despite a good combustion, can lead to an increase in $\mathrm{NO}_{\mathrm{X}}$ formation. Cameretti et al. [8] investigated the suitability of liquid and gaseous fuels for use in a lean premixed MGT combustor and also assessed the potential of external EGR for $\mathrm{NO}_{X}$ reduction. Published literature also reports other promising solutions for combustion completion improvements and $\mathrm{NO}_{\mathrm{X}}$ mitigation, such as the increase in pilot injection rate and modification to the pilot location, respectively, [9]. Mărculescu et al. [13] analyzed the change in performance when the MGT is adapted to burn alternative low-quality gas fuel produced by biomass gasification with heating values 3 to 5 times lower than methane. At constant heat flow rate in the combustion chamber, the gas flow rate increases to keep the temperature of the flue gases constant. Then, the gross electric power increases but the net electric output decreases compared to methane use. Nicolosi et al. [14] assessed the effect of the variation of the operating conditions on the performance of the recuperator and, therefore, of the whole MGT. The use of alternative fuels with low LHV shifts the operative points of the turbomachines; in general, compression ratio is reduced, as is the flow rate of the compressor. Therefore, attention must be paid to the compressor stall limit. The recuperator shows a slight variation in the temperature of the fluids, but a higher efficiency is recorded as the flow rate is typically reduced and a better heat recovery performance can be obtained.

Hasini et al. [15] performed a CFD investigation, using ANSYS Fluent, of flow, combustion process and pollutant emission using natural gas, liquefied natural gas and syngas of different composition on a combustor can-type. The prediction of pollutant species concentration at combustor exit shows significant reduction in $\mathrm{CO}_{2}$ and $\mathrm{NO}_{\mathrm{X}}$ for syngas combustion compared to conventional natural gas and LNG combustion. Ammar et al. [16] examined four syngas fuel compositions which differed by $\mathrm{H}_{2} / \mathrm{CO}$ ratios. The volume of $\mathrm{CO}_{2}$ at the exhaust decreases with the increase in hydrogen content, while the $\mathrm{NO}$ emissions increase as the hydrogen content increases. However, syngas fuel has lower emissions of $\mathrm{NO}$ and $\mathrm{CO}_{2}$ and higher emissions of $\mathrm{CO}$ than those from natural gas fuel at the same operating conditions. In [17] it is demonstrated that the reactivity of the syngas mixture is governed by hydrogen chemistry for CO concentrations lower than $50 \%$ in the fuel mixture, while for higher CO concentrations, an inhibiting effect of $\mathrm{CO}$ is observed.

The syngas supply and combustion efficiency of the MGT Capstone C30 were already experimentally investigated in $[18,19]$, by testing different compositions that have various hydrogen and carbon monoxide ratios. It was found that the high amount of hydrogen content in syngas leads to an increase in the combustion efficiency and emits more NOx emissions. Indeed, higher hydrogen content elongates the flame because of the presence of more $\mathrm{H}$ radicals. This $\mathrm{H}$ radical promotes the chain branching and chain propagation, enhancing the reaction zone length and flame speed. Thus, the flammability limits are extended so that the flame is able to achieve stability at leaner conditions. On the other hand, $\mathrm{CO}$, emissions are released when the combustion efficiency is low and increase with the $\mathrm{CO}$ content in the syngas.

Hydrogen fuel is considered another appealing alternative to fossil fuels, potentially capable of relieving global $\mathrm{CO}_{2}$ emissions. Pambudi et al. [20] analyzed the impact of hydrogen in the power generation sector by comparing a base scenario without hydrogen with one in which hydrogen 
substitutes part of the fossil fuel supply from 2020 onwards. The use of hydrogen would result in substantially less $\mathrm{CO}_{2}$ being released into the atmosphere, leading to emission reductions of nearly $60 \%$ by 2050 . However, the percentage of hydrogen to the energy supply must be around $10 \%$ due to the increased NOx emissions.

The suitability of the use of $\mathrm{CH}_{4} / \mathrm{H}_{2}$ blends in MGT was investigated in various ratios both in lean premixed and in RQL combustors by Tuccillo et al. [10], who found that the lean premixed combustor type appears more prone to flashback at lower $\mathrm{H}_{2}$ concentrations and that RQL combustors offer a better chance for $\mathrm{NO}_{X}$ control via the separate injection of methane and hydrogen. However, the increased combustor outlet temperature might be a problem from a turbine blade thermal resistance point of view, as well as combustor design modifications in the dilution zone, which might be necessary [11].

In this regard, the design and construction of a $100 \mathrm{~kW}$ pure hydrogen fueled MGT is illustrated in [21]. The progressive optimization of the compressor-combustor system is achieved starting from a full thermodynamic cycle analysis and though CFD simulations in steady and transient conditions.

In [22], steam injection (STIG) is proposed as a solution to limit the drawbacks caused by the use of alternative fuels in MGT. A proper injection strategy is evaluated to enhance the electric power by $24 \%$ and the electric efficiency up to $29 \%$. Moreover, steam injection in the combustion chamber, allows for dramatically reduced $\mathrm{CO}$ and NOx emissions. In particular, the higher $\mathrm{CO}$ emissions can be reduced by injecting the majority of the steam in the dilution zone, allowing higher temperatures, which enhance the $\mathrm{CO}$ oxidation, while the NOx emissions can be reduced by injecting part of the steam in the pilot zone, where the majority of the NOx forms.

However, despite the scientific effort witnessed by a large number of publications in the field, none of the abovementioned approaches allowed us to solve all the issues related with the use of alternative fuels within MGT designed for natural gas, which still presents several criticalities.

In the present study, a hybrid micro gas turbine/solar field plant was considered to evaluate the contribution of the solar radiation to increase the combustor inlet temperature for improving the efficiency of a recuperated thermal cycle. As a result of the introduction of the solar field, the gas turbine operating conditions change during the day, varying the fuel input requirement with considerable effect on the exhaust emissions.

Additionally, two fuels able to reduce $\mathrm{CO}_{2}$ and pollutant emissions-hydrogen and a syngas from agriculture biomass-were tested and compared with natural gas as a reference fuel. The authors present a thermodynamic model of a CHP plant integrated with a solar field by Thermoflex ${ }^{\circledR}$ solver. The micro gas turbine is a $30 \mathrm{~kW}$ Capstone $\mathrm{C} 30$, able to produce electric and thermal power (hot water). The syngas considered is obtained from gasification of olive pits biomass [1], which is present copiously in Southern Italy. As a matter of fact, several agriculture products are considered in the literature as potential fuels [23-26], depending on geographic sites rich in a particular biomass.

The thermal cycle analysis was carried out over daily and yearly periods and it aimed, in particular, at estimating the effectiveness of thermal storage in the solar field as a feasible way to extend both energy saving and pollutant reduction to nightly hours operation. The analysis compared the solar assisted CHP plant performance for several fuels and a final second law analysis aimed at the estimation of the increase in residual mechanical energy potential obtained by means of the solar contribution.

In the final part of this paper, to evaluate the pollutant emissions, in particular NOx, a CFD calculation of MGT combustor was performed for each fuel, considered by using ANSYS Fluent solver. Many studies were performed by the authors themselves to evaluate the behavior of this combustor by varying fuels and operating conditions $[3,5,27,28]$.

\section{Thermodynamic Analysis}

With the aim of assessing the suitability of the use of alternative fuels in a hybrid solar field-mGT plant, from a retrofit point of view, the model of a Capstone C30 micro Gas Turbine (mGT), whose characteristics are described in Table $1[1,3,4,7,9,10]$, was implemented in a zero-dimensional solver (Thermoflex). Additionally, a solar field with storage was integrated in the plant schematic, 
as depicted in Figure 1 and the mGT was simulated in cogenerating mode. Finally, the plant was provided with a Heat Recovery Unit placed downstream of the recuperator \#5 (Figure 1), on the exhaust gas path. Concerning the solar field, although the adoption of parabolic trough collectors with a heat transfer fluid —namely, a diathermic oil—is known to be less efficient than solar fields with direct radiation from heliostats to the operating fluid in the micro gas turbine $[1,4,5]$, the former solution was chosen as it is less expensive and it allows an easier thermal storage. Additionally, the solar field was sized defining a solar network exit temperature of $420{ }^{\circ} \mathrm{C}$, referring to the irradiance curve of July to obtain a reduced collector area for cost containment, although a thorough economic analysis was not performed. For additional details about the solar field, the reader is referred to Table 2.

Table 1. C30 micro gas turbine datasheet, $[1,3,4,7,9,10]$.

\begin{tabular}{cc}
\hline Quantity & Value \\
\hline Recuperator Efficiency & 0.85 \\
Pressure Ratio & 3.45 \\
Compressor Polytropic Efficiency & 0.78 \\
Turbine Polytropic Efficiency & 0.80 \\
TIT (K) & 1173 \\
Net Power Output $(\mathrm{kW})$ & $28(+0 /-1)$ \\
Speed (rpm) & 96,000 \\
Exhaust Gas Temperature $(\mathrm{K})$ & 548 \\
Exhaust Gas Mass Flow Rate $(\mathrm{kg} / \mathrm{s})$ & 0.3 \\
\hline
\end{tabular}

\begin{tabular}{|c|c|}
\hline 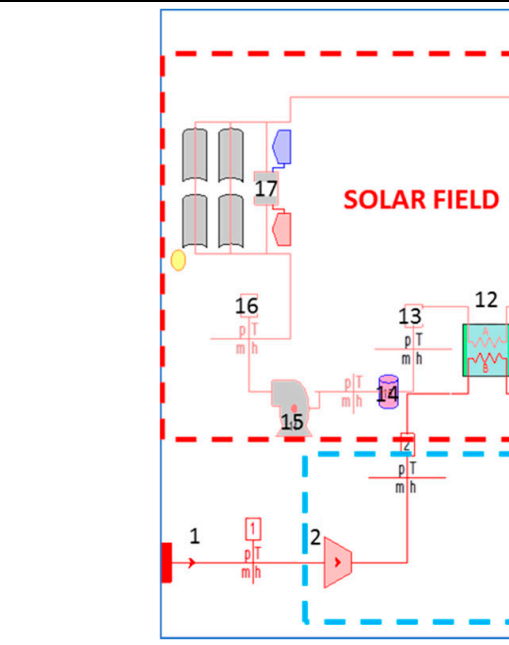 & 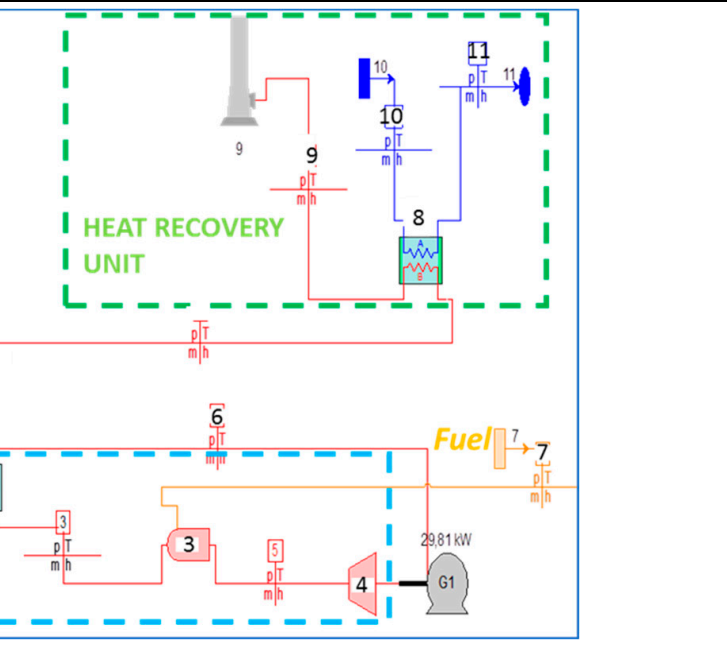 \\
\hline $1=$ air at ambient condition & $9=$ exhaust gas conditions \\
\hline $2=$ compressor & $\begin{array}{l}10 / 11=\text { conditions of the water entering and } \\
\text { leaving the boiler }\end{array}$ \\
\hline $3=$ combustor & $12=$ solar field exchanger \\
\hline $4=$ turbine & $13=$ diathermic oil conditions after exchanger $\# 12$ \\
\hline $5=$ recuperator & $14=$ diathermic oil tank \\
\hline $6=$ turbine exhaust gas conditions & $15=$ diathermic oil pump \\
\hline $7=$ input fuel conditions & $17=$ solar field (collectors and storage) \\
\hline $8=$ recovery boiler & $\begin{array}{l}16 / 18=\text { conditions of the diathermic oil entering } \\
\text { and leaving the solar field }\end{array}$ \\
\hline
\end{tabular}

Figure 1. Plant scheme. 
Table 2. Solar field characteristics.

\begin{tabular}{cc}
\hline Quantity & Value \\
\hline Mass flow per operating flow path $(\mathrm{kg} / \mathrm{s})$ & 0.2008 \\
Direct normal irradiance $\left(\mathrm{W} / \mathrm{m}^{2}\right)$ & 842.4 \\
Network inlet temperature $\left({ }^{\circ} \mathrm{C}\right)$ & 274.4 \\
Network exit temperature $\left({ }^{\circ} \mathrm{C}\right)$ & 419.7 \\
Net heat absorbed by field $(\mathrm{kW})$ & 75 \\
Receiver tube outside diameter $(\mathrm{mm})$ & 30 \\
Receiver tube material & $\mathrm{T} 22$ \\
Reflector aperture width $(\mathrm{m})$ & 1.353 \\
Collector field area $\left(\mathrm{m}^{2}\right)$ & 5 \\
Reflective area $\left(\mathrm{m}^{2}\right)$ & 1125.8 \\
Number of reflector rows per & 382 \\
Number of hours of storage $(\mathrm{h})$ & 6 \\
Storage hot tank temperature $\left({ }^{\circ} \mathrm{C}\right)$ & 415 \\
Storage cold tank temperature $\left({ }^{\circ} \mathrm{C}\right)$ & 280 \\
\hline
\end{tabular}

The heat collected by solar field was provided to the air flowing through the mGT via the recuperator \# 12 (Figure 1), placed downstream of the mGT's compressor. Consequently, the solar contribution was expected to provide a two-fold effect:

- The increased air temperature at combustor inlet was expected to moderately reduce the fuel consumption for a given firing temperature;

- An enhanced performance of the CHP power plant was expected, thanks to the higher temperatures reached by the exhaust gases at the inlet of heat recovery unit.

Mass and energy balances for the abovementioned plant, of which a schematic representation is provided in Figure 1, were solved by a zero-dimensional solver (Thermoflex).

Firstly, a thermodynamic analysis was performed with and without energy storage to highlight its potential benefit on the daily fuel demand considering 5 th July, for which hourly ambient temperature is depicted in Figure 2. Secondly, the thermodynamic analysis was extended, for the thermal storage case only, including different fuels. More specifically, three fuels were considered-namely conventional natural gas, which was treated as the baseline case for comparisons; syngas from agriculture waste biomass, (i.e., olive pits) and pure hydrogen. Syngas and natural gas compositions are reported in Table 3.

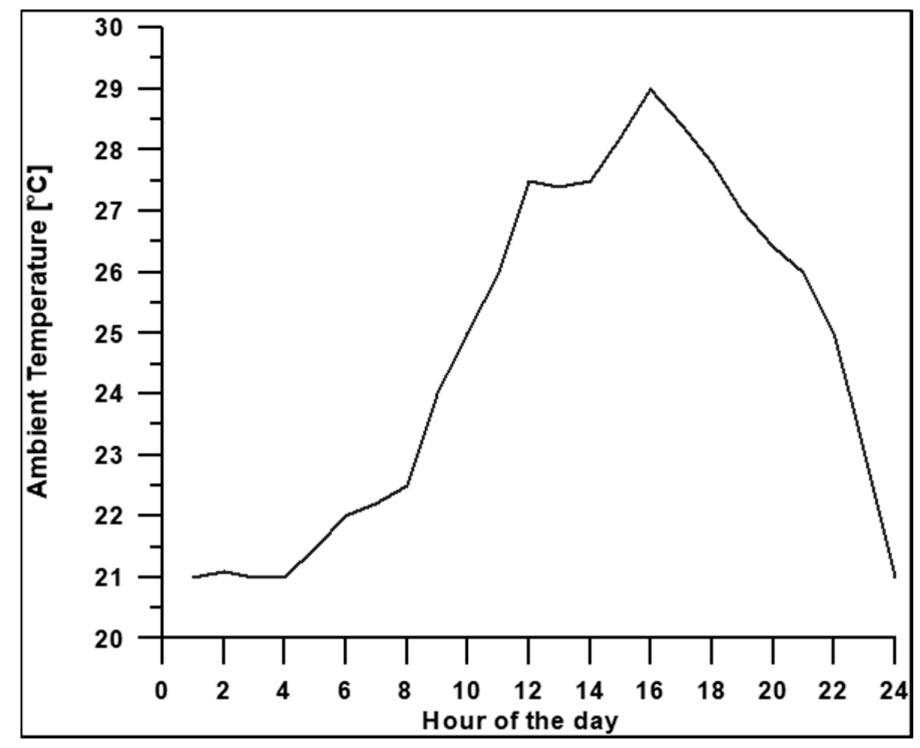

Figure 2. Hour-to-hour ambient temperature variation on 5th July [29]. 
Table 3. Syngas (from olive pits) and NG compositions.

\begin{tabular}{cccccccccccccc}
\hline \multicolumn{1}{c}{ Fuel } & \multicolumn{1}{c}{ Composition (Mole\%) } & \multicolumn{1}{c}{ LHV (kJ/kg) } \\
\hline & $\mathbf{C H}_{\mathbf{4}}$ & $\mathbf{C}_{\mathbf{2}} \mathbf{H}_{\mathbf{6}}$ & $\mathbf{C}_{\mathbf{3}} \mathbf{H}_{\mathbf{8}}$ & $\mathbf{C}_{\mathbf{4}} \mathbf{H}_{\mathbf{1 0}}$ & $\mathbf{H}_{\mathbf{2}}$ & $\mathbf{H}_{\mathbf{2}} \mathbf{O}$ & $\mathbf{C O}$ & $\mathbf{C O}_{\mathbf{2}}$ & $\mathbf{H}_{\mathbf{2}} \mathbf{S}$ & $\mathbf{C O S}$ & $\mathbf{N}_{\mathbf{2}}$ & $\mathbf{A r}$ & \\
\hline Natural Gas & 92.00 & 3.70 & 1.00 & 0.25 & -- & -- & -- & 0.15 & - & -- & 2.90 & - & 46,280 \\
Syngas & 12.17 & -- & -- & -- & 11.90 & 3.164 & 22.03 & 12.36 & 3.164 & 0.001 & 37.91 & 0.4545 & 7514 \\
\hline
\end{tabular}

However, it is to be considered that different fuels require slight modifications to the plant layout to account for either fuel compression to the combustion chamber pressure or pressure regulation. Nonetheless, it was deemed that such modifications might have introduced a bias in the results, and so in the fuels comparison. Hence, in order to leave the plant unmodified from case to case, still holding the likelihood of the results, the following approach was followed by the authors:

- For the natural gas case, the hypothesized scenario is a delivery via net. Hence, a compression power was accounted in the plant net power computation, based on the fuel mass flow rate, compression ratio (delivery-combustion chamber) and compressor polytropic efficiency.

- For the syngas case, the envisaged scenario is an on-site production. Consequently, plant net power was diminished by the compression power from ambient pressure to reaction chamber pressure, and further to combustion chamber pressure, of the reacting air flow rate for syngas production.

- For the hydrogen case, the purchase of pressurized gas from a producing plant is considered the most likely scenario. Accordingly, being the average storage pressure available on the Italian market about 200 bar, no compression work was accounted in the plant net power computation.

Based on the above-mentioned assumptions, the thermodynamic analysis was conducted accounting for ambient temperature variation during the day and the year by imposing as a boundary condition the ambient temperature retrieved from [29], and the results were compared both on an hour-to-hour basis for a given day, as well as averaged monthly, taking power, efficiency, thermal power supplied by the fuel, heat available to $\mathrm{HRU}$ and $\mathrm{CO}_{2}$ emissions as figures of merit. Furthermore, an analysis on the cogeneration process and its characteristic indexes was also performed. Additionally, due to the increased amount of recoverable heat from exhausts at higher temperatures, a proper exergy analysis was carried out to identify the potential of still available mechanical energy.

In the next section, the results of the thermodynamic analysis together with those of cogeneration and exergy analysis are presented.

\section{Results}

\subsection{Storage}

The first analysis carried out in the present work aimed at assessing the potential of the thermal storage in relieving fuel demand during night hours, as well as in low irradiance conditions. To do so, for the plant presented in Section 2 (Figure 1), a $24 \mathrm{~h}$ operation was simulated in a quasi-steady manner with and without thermal energy storage considering ambient temperature variation, representative of 5 July (Figure 2), for south Italian latitude, namely that of Naples.

This day was chosen as it is usually characterized by a high average irradiance and high average ambient temperature, with the two aspects having conflicting effects. The former leads to an increase in the solar contribution to the plant power output, whereas the latter lowers the net power output from the mGT due to the increase in the work absorbed by the compressor. In Figure 3, the percentage of heat from collectors and storage are represented during a day.

In Figure 4 the efficiency (referred only to fuel supply) with and without storage is compared. No substantial difference can be noticed in the central hour of the day (9-15), when the irradiance is maximum: in fact, in such cases most if not all the non-fuel input energy is provided by the solar field rather than the storage, even for the thermal energy storage case, shown in Figure 3. For night and low-irradiance hours, $0-6$ and 17-24, substantial differences can be noticed. This occurrence 
is explained by a larger fuel contribution in the no-thermal storage scenario, shown in Figure 5, which lowers the fuel-based efficiency value. Conversely, thermal energy storage provides about $8.5 \%$ energy saving during the night.

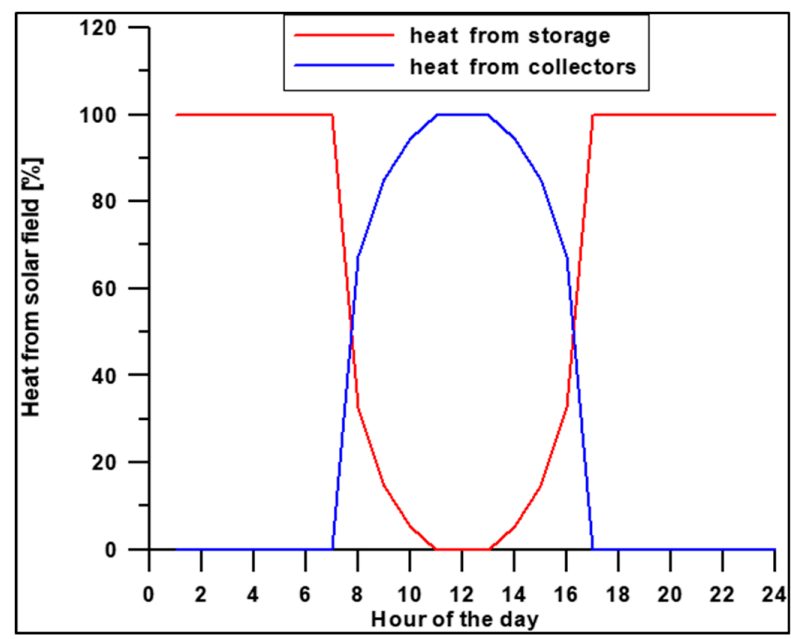

Figure 3. Percentage of heat to network from solar field.

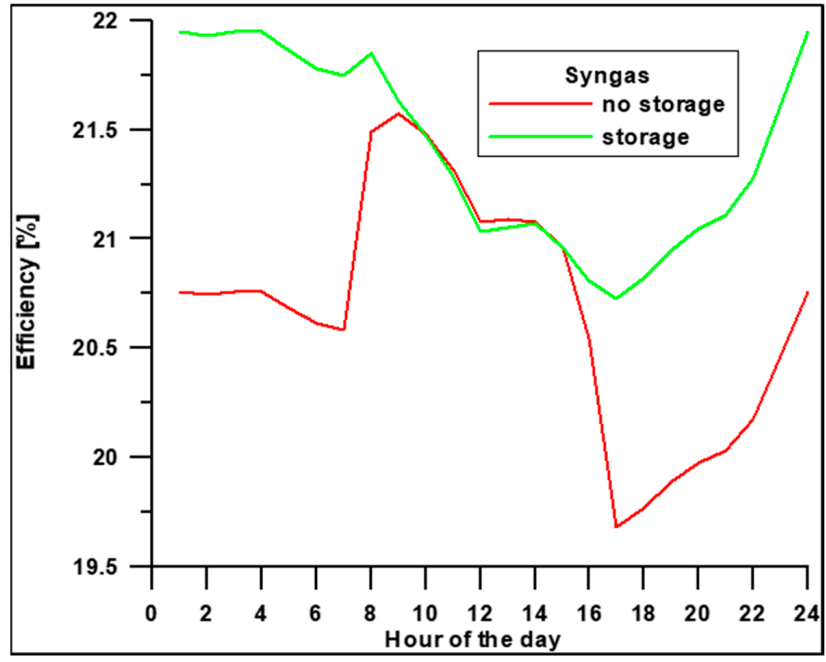

Figure 4. Efficiency versus day hours (Syngas fuel).

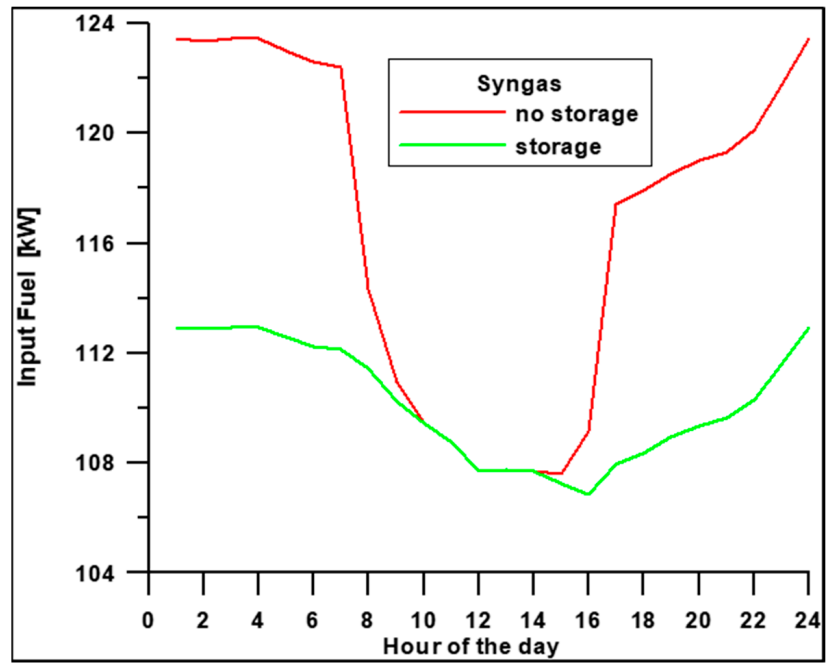

Figure 5. Input fuel with and without storage (Syngas fuel). 
Concerning the plant net power output, shown in Figure 6, contrary to daylight hours when almost the same value is achieved, lower power output is obtained during night hours when storage is active due to the pressure drops of exchanger \#12 of the solar field.

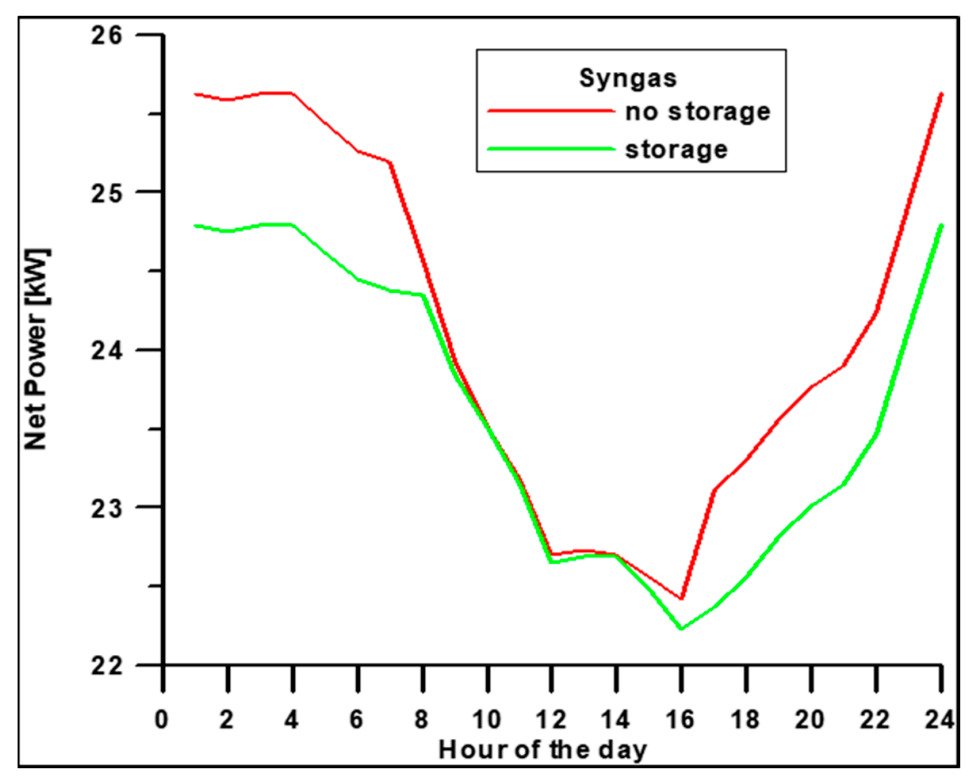

Figure 6. Net power versus day hours (Syngas fuel).

Furthermore, the presence of the storage allows us to keep the input power to the Heat Recovery Unit constant during night hours too, shown in Figure 7. Conversely, a sharp reduction in input power to the HRU is noticed when no thermal energy storage is considered.

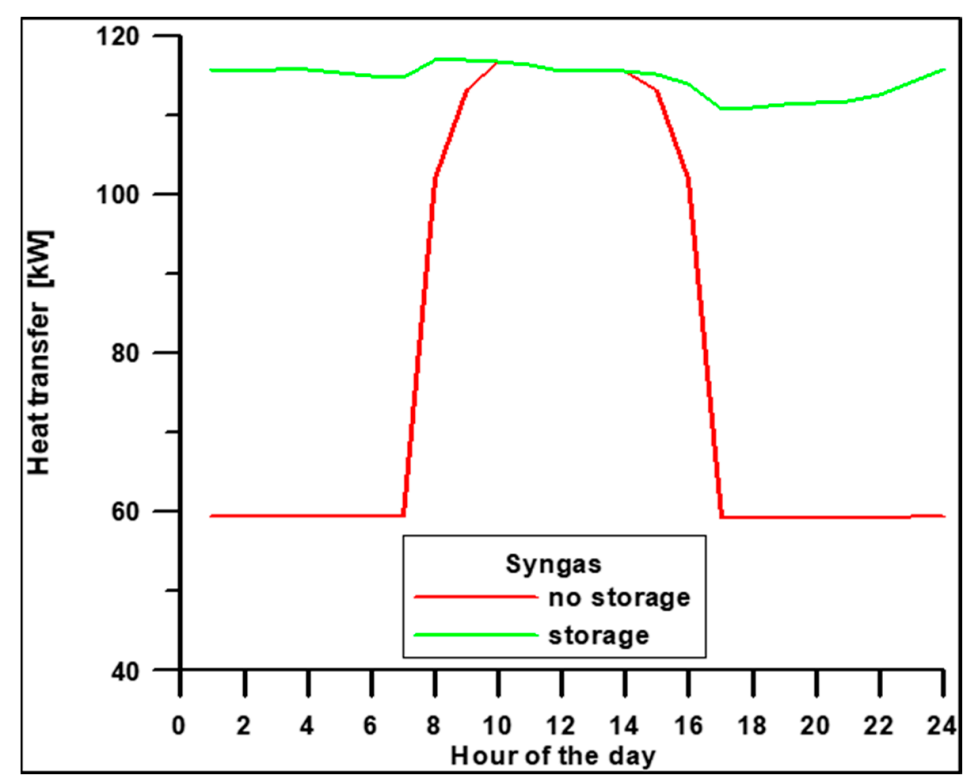

Figure 7. Heat transferred to Heat Recovery Unit.

\subsection{Fuel Comparison (With Storage)}

In this section, a comparison between the plant performance fed by different fuels and in the presence of a storage system, is made. The three gaseous fuels considered (hydrogen, syngas and natural gas) present different LHV, which is calculated by the code, based on molar percentage of chemical species. 
As a consequence, the fuel mass flow rate during operation varies considerably, as reported in Table 4, considering the day-averaged values. The fuel mass flow rates are obtained fixing the same value of TIT. As expected, the hydrogen requires a much lower flow rate than the other two fuels due to the high LHV value, while the syngas requires the highest.

Table 4. Lower Heating Value (LHV) and daily average mass flow rates for the three fuels considered.

\begin{tabular}{cccc}
\hline Fuel & Hydrogen & Syngas & Natural Gas \\
\hline LHV $(\mathrm{kJ} / \mathrm{kg})$ & 120,067 & 7514 & 46,280 \\
Fuel mass flow rate $(\mathrm{kg} / \mathrm{s})$ & $9 \times 10^{-4}$ & $1.54 \times 10^{-2}$ & $2.1 \times 10^{-3}$ \\
\hline
\end{tabular}

As a first step, the fuel comparison was performed in a single day to evaluate the trends on an hour-to-hour basis under variable solar irradiance. Figure 8 shows a comparison of the net power (including fuel compression power) produced by the plant for the three fuels considered as a function of the hour. It is worth mentioning that, for net power computation, the fuel compression power was accounted where applicable, in accordance with the scenarios described in Section 2-e.g., both syngas and natural gas. Interestingly, almost no difference was noticed between syngas and natural gas cases, whereas large variations were provided by the hydrogen.

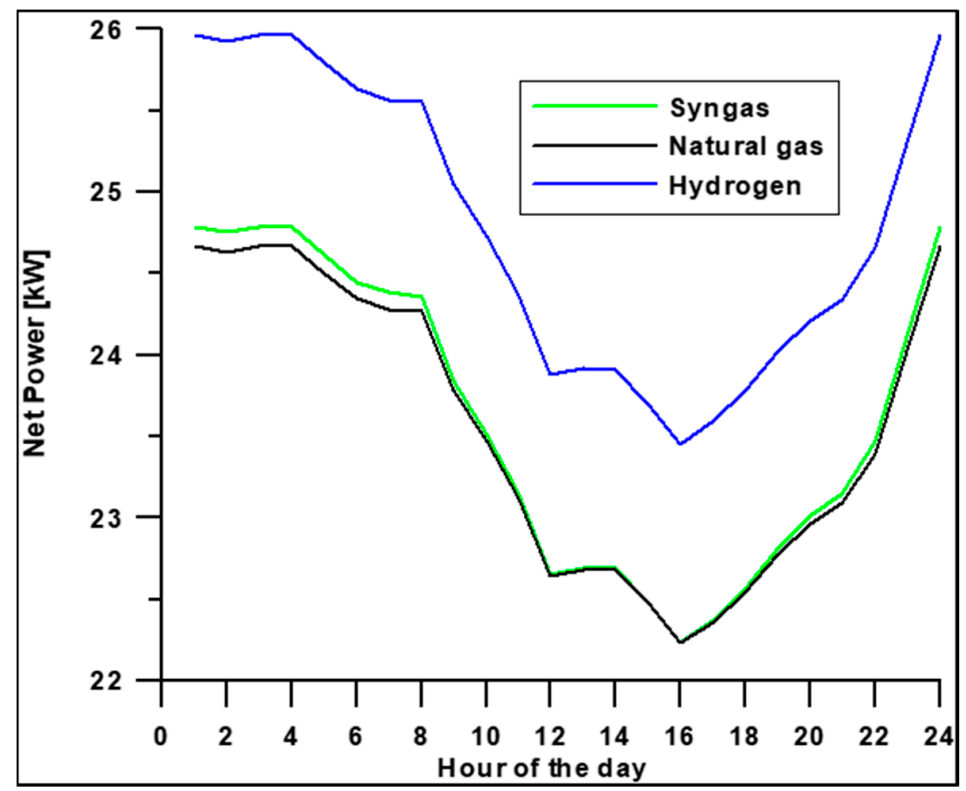

Figure 8. Net power calculated for the three fuels.

In Figure 9 the thermal efficiency referred to fuel input, computed according to Equation (1), is represented. Both power and thermal efficiency diagrams show a better result for hydrogen, whereas concerning syngas and natural gas, despite the very similar power output trends, substantially different efficiency values were achieved by the fuels, with the lowest one attained by the syngas. The latter is in fact compensated by a much larger input power provided by the fuel in the syngas case, Figure 10 .

$$
\eta=\frac{P_{e l}}{\dot{m}_{f} * L H V}
$$




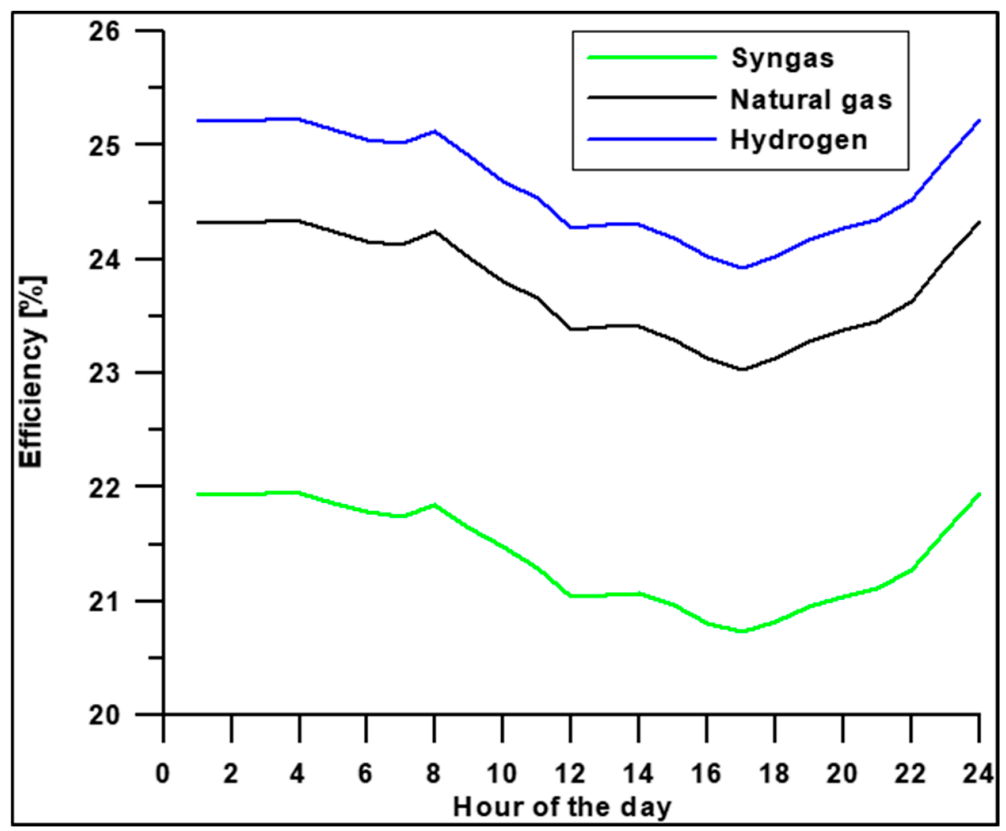

Figure 9. Thermal Efficiency (LHV) calculated for the three fuels.

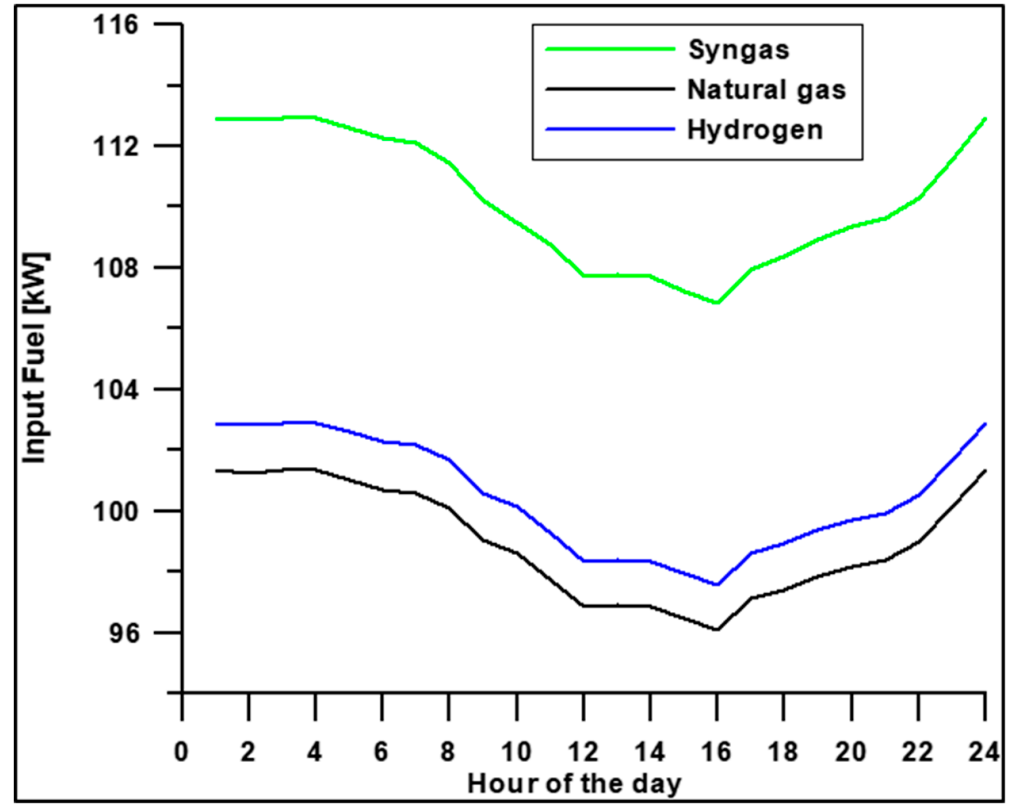

Figure 10. Input fuel power versus day hours.

Finally, in Figure 11, the heat transferred to the Heat Recovery Unit is shown for the three fuels and, from this point of view, the best results are achieved by the syngas with the largest heat availability through the whole day.

In view of the opposite trends achieved by syngas and hydrogen fuels for net power output and Heat Transfer to the HRU figures of merit, a thorough cogeneration and exergy analysis on heat exchanger \#8, shown in Figure 1, were considered fundamental to assess the overall performance. Cogeneration and exergy analysis are presented in Sections 3.3 and 3.4, respectively.

In a second step, the fuel comparison was extended to the whole year by varying irradiance and ambient temperature and the day-averaged results are presented on a month-to-month basis in Figures 12-17. It is worth mentioning that results presented in Figures 12-14 (i.e., power, thermal efficiency (LHV) and heat transferred to the HRU for the three fuels) are averaged on daylight hours 
(from 8 a.m. to 7 p.m.) only, whereas Figures 15 and 16 show results that have been averaged on night hours only, to enhance the effect of the thermal storage on fuel saving and energy availability during night.

All charts, Figures 12-16, show a valley for the hottest months-i.e., during summer. In fact, this season is characterized by higher average ambient temperature and larger solar irradiance. The former tends to increase compressor work and lower compressor mass flow rate, thus lowering plant efficiency, net power output and heat transferred to the HRU; the latter tends to alleviate this trend thanks to the heat collected by the solar field. Nonetheless, in the present case the effect of the solar irradiance is not large enough to compensate for the ambient temperature effect. Indeed, a solar field large enough to compensate ambient temperature effect would potentially compromise the economic viability of the plant itself.

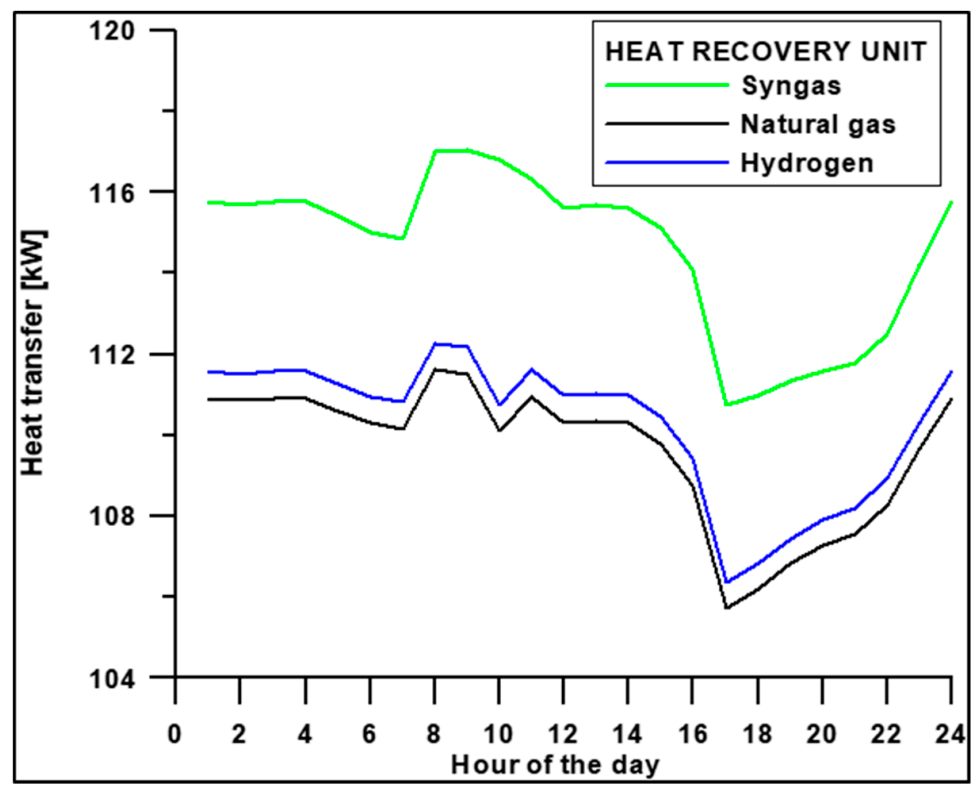

Figure 11. Heat transfer in heat recovery unit in a day.

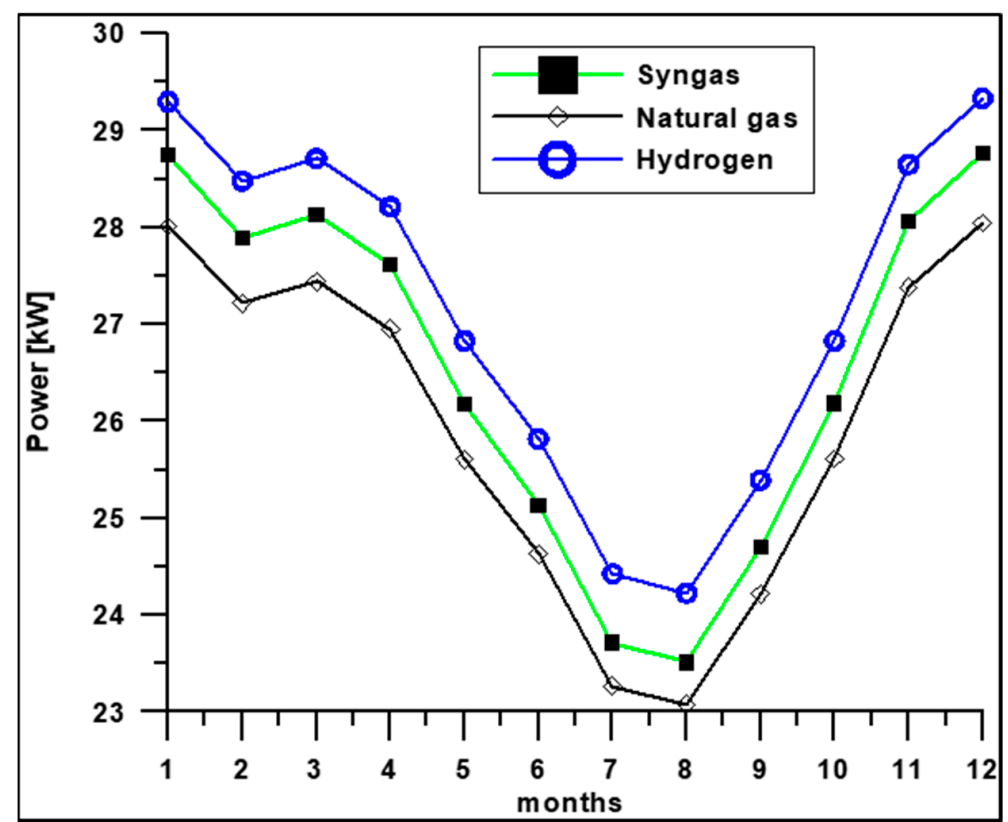

Figure 12. Net Power in a year in diurnal hours. 


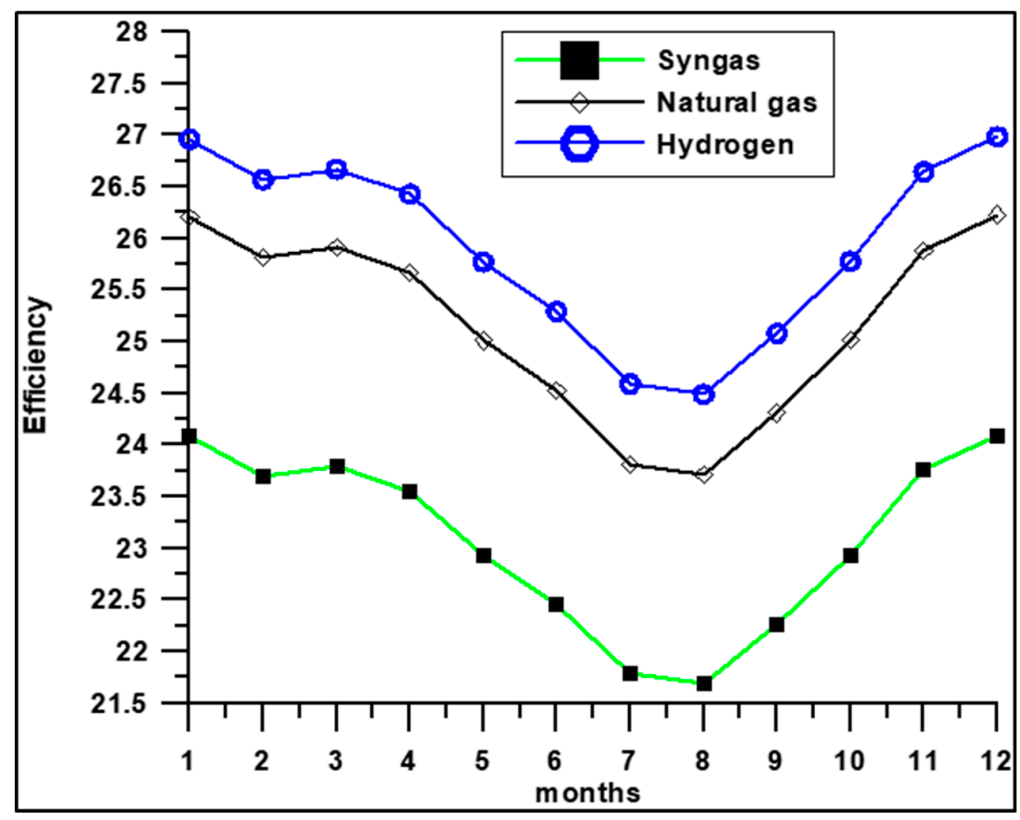

Figure 13. Thermal efficiency (LHV) in a year in diurnal hours.

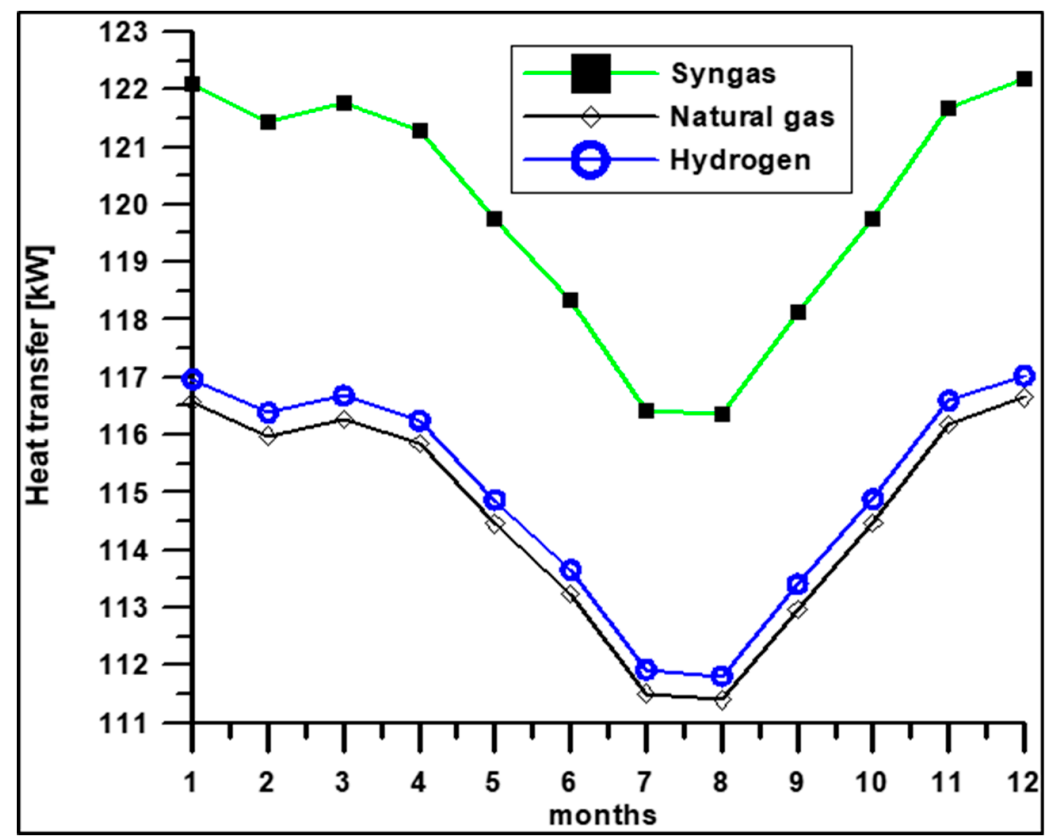

Figure 14. Heat transfer in cogeneration unit during year.

Concerning month-to-month power output, shown in Figures 12 and 15, a similar relative position among fuels is achieved with respect to hour-to-hour results, shown in Figure 8, with natural gas-syngas differences widened for daylight average. Likewise, syngas showed the lowest efficiency for the results on daily and yearly bases, shown in Figures 9 and 13, as well as the largest heat transferred to the HRU, both on daily and yearly bases, shown in Figures 11,14 and 16. The same consideration about the relative positioning are valid for the other two fuels, with exceptions made for natural gas-hydrogen heat transferred to the HRU on night hour on average during summer, shown in Figure 16, when the two curves are swapped. 


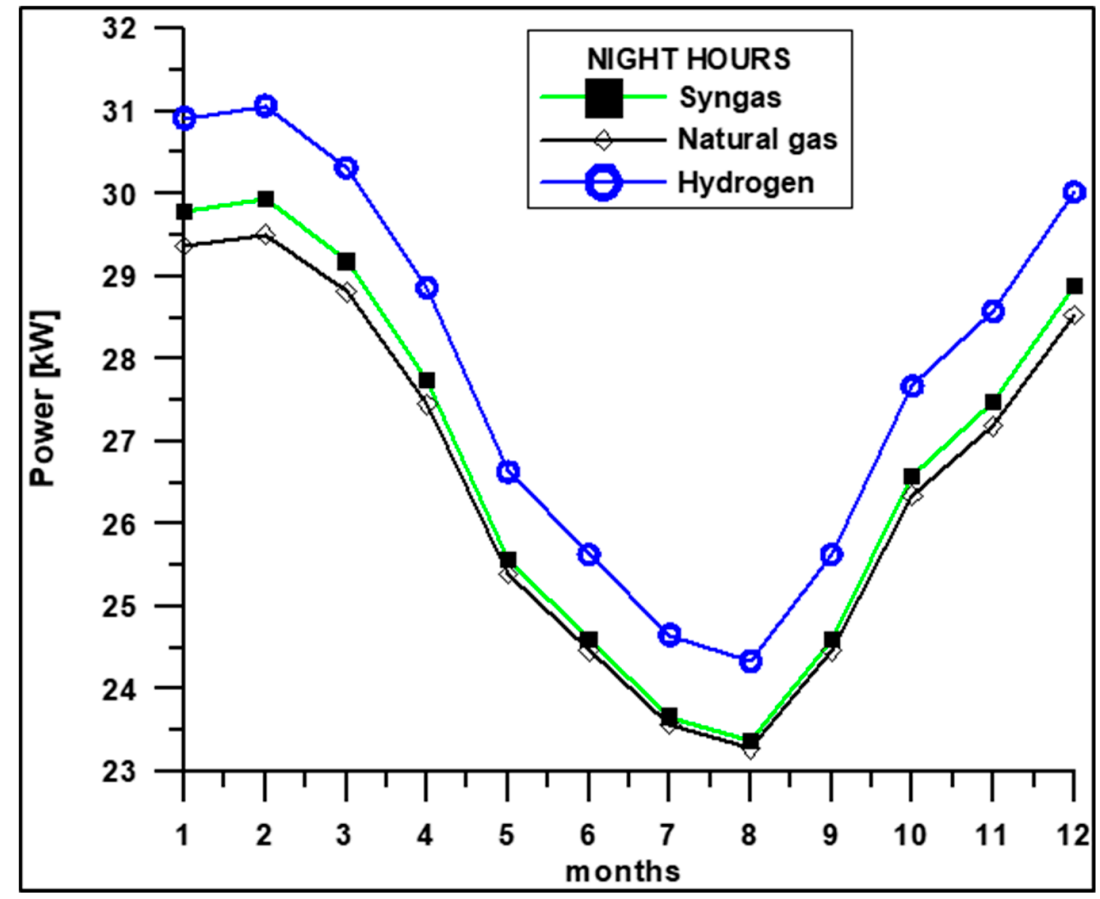

Figure 15. Net power in a year in night hours.

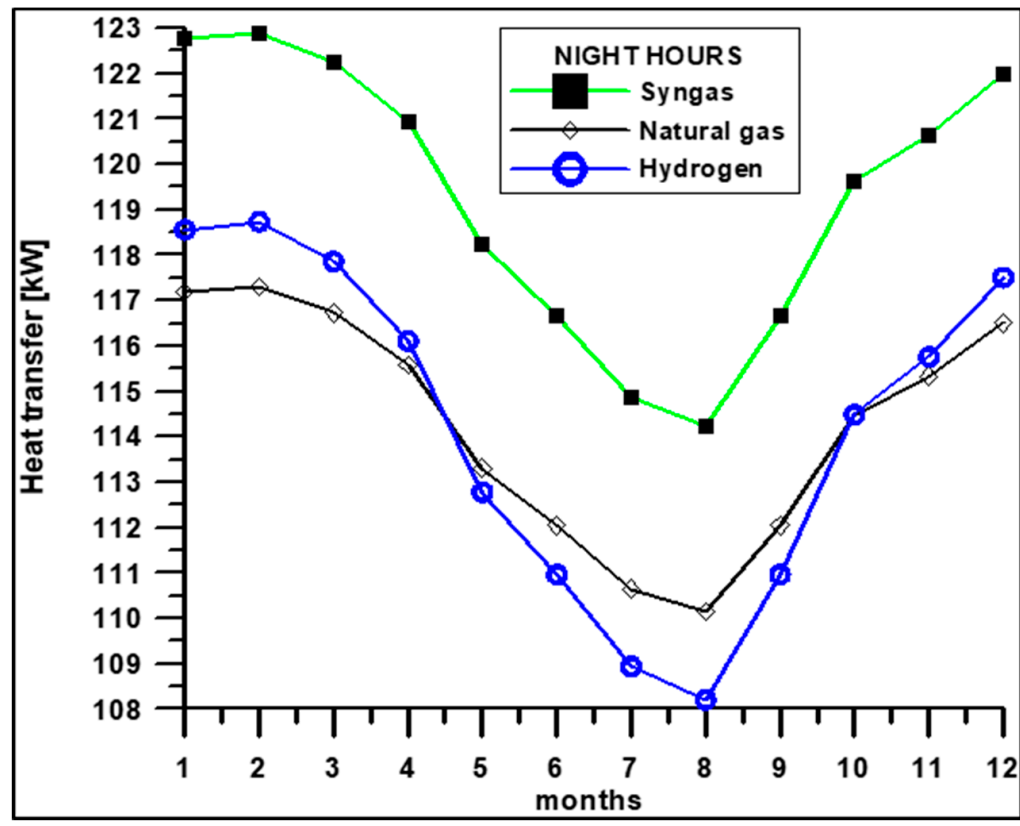

Figure 16. Heat transfer in cogeneration unit during year (night hours).

Finally, in Figure 17, the $\mathrm{CO}_{2}$ emissions during a solar year are presented along with the yearly averaged values in Table 5, expressed in $\mathrm{kg} / \mathrm{kWh}$, compared against the baseline case represented by the mGT plant without solar field. As expected, being the hydrogen, a non-carbon-based fuel, its $\mathrm{CO}_{2}$ emissions are negligible. Conversely, it appears clearly that the introduction of the solar field allowed us to reduce the average specific $\mathrm{CO}_{2}$ emission, with respect to the baseline case. Instead, the adoption of syngas fuel led the average specific $\mathrm{CO}_{2}$ emission to increase. In this regard, one should note that syngas, being a fuel of vegetable origin, is considered neutral by emissions regulations. 


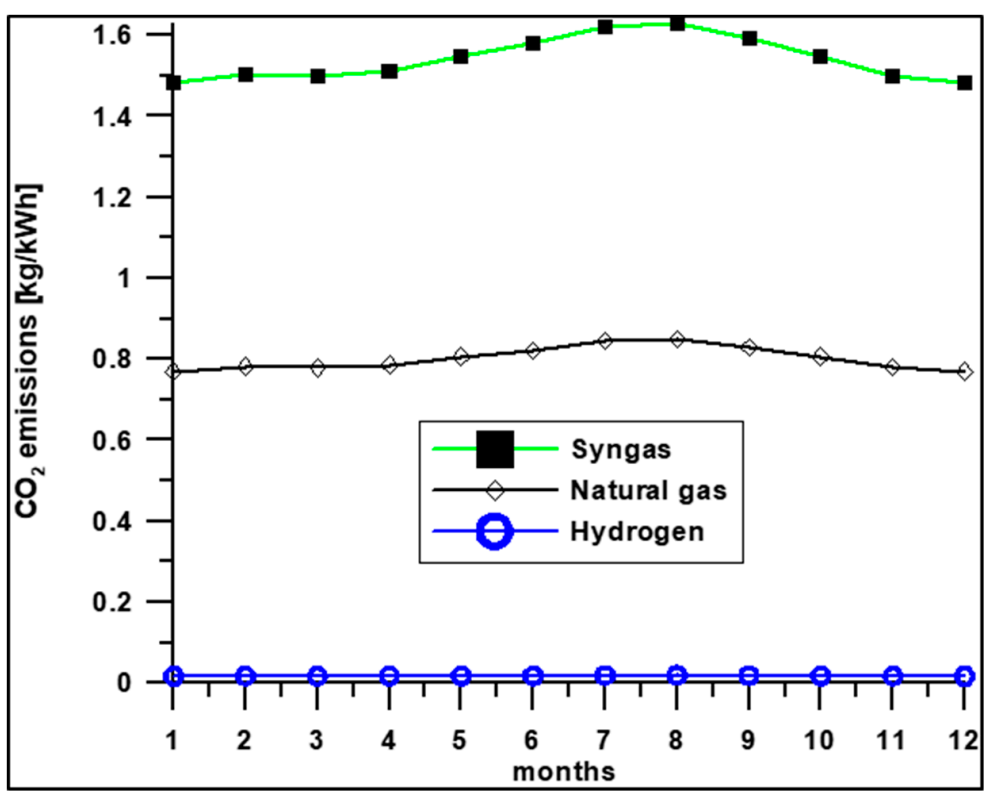

Figure 17. $\mathrm{CO}_{2}$ emissions during year (diurnal hours).

Table 5. Year-averaged $\mathrm{CO}_{2}$ emissions.

\begin{tabular}{ccccc}
\hline Fuel & Hydrogen & Syngas & Natural Gas & Baseline \\
\hline $\mathrm{CO}_{2}$ emissions $(\mathrm{kg} / \mathrm{kWh})$ & $1.8 \times 10^{-2}$ & 1.52 & 0.79 & 0.85 \\
\hline
\end{tabular}

\subsection{Cogeneration Indexes}

Being the plant in a cogeneration arrangement and, in view of the high thermal power available at the HRU section, as well as its dependency on the chosen fuel, it was deemed appropriate to carry out a thermodynamic analysis considering the cogeneration, evaluating its characteristic indexes. Following Italian legislation, the energy saving provided by the cogeneration system was computed according to Equations (2)-(4), considering the solar field and storage.

$$
R I S P=\frac{E_{C H P}}{\eta_{e} \text { REF }}+\frac{H_{C H P}}{\eta_{\text {th } R E F}}-F_{C H P},
$$

where $E_{C H P}$ is the electricity produced by the cogeneration unit $(\mathrm{kWh}) ; H_{C H P}$ is the useful thermal energy produced by the cogeneration unit $(\mathrm{kWh}) ; \eta_{e, R E F}$ and $\eta_{\mathrm{th}, R E F}$ are, respectively, the conventional electric and thermal efficiency, used for the comparison; $F_{C H P}$ is the fuel energy used by the cogeneration unit (kWh).

Another characteristic parameter for cogeneration is the Utilization factor, expressed as follows, if referring only to input fuel:

$$
\text { FEUF }=\left(P_{e l}+P_{t h}\right) /\left(\dot{m}_{f} L H V\right),
$$

and, if referred to the overall heat supplied (fuel and heat absorbed by solar field), as:

$$
F E U F=\left(P_{e l}+P_{t h}\right) /\left(\dot{m}_{f} L H V+\dot{Q}_{s o l}\right),
$$

where $P_{e l}$ is the net electrical power, $P_{t h}$ the output thermal power, $\dot{m}_{f}$ is the fuel mass flow rate and $\dot{Q}_{s o l}$ is the solar heat transferred to plant. The results of the cogeneration analysis are summarized in Table 6-more specifically, averaged powers, efficiency and cogeneration indexes are reported for the three investigated fuels in the current plant arrangement, as well as a baseline case for comparison, represented by the mGT only fueled by natural gas. 
Table 6. Overall plant performance and cogeneration index for the investigated plant for three different fuels; the baseline case is the mGT fueled by NG without solar field and energy storage.

\begin{tabular}{ccccc}
\hline Fuel & Hydrogen & Syngas & Natural Gas & Baseline \\
\hline LHV $(\mathrm{kJ} / \mathrm{kg})$ & 120,067 & 7514 & 46,280 & 46,280 \\
Fuel Energy Input $(\mathrm{kW})$ & 105.4 & 115.82 & 103.78 & 115.48 \\
Input Solar Energy $\dot{Q}_{\text {sol }}(\mathrm{kW})$ & 72.12 & 69.84 & 72.45 & - \\
Thermal Power output $P_{\text {th }}(\mathrm{kW})$ & 114.37 & 119.62 & 114.45 & 51.52 \\
Net Power $P_{\text {el }}(\mathrm{kW})$ & 27.52 & 26.67 & 26.89 & 28.14 \\
Thermal Efficiency $(\mathrm{LHV})$ & 26.11 & 23.03 & 25.87 & 24.36 \\
Thermal Efficiency $(\mathrm{LHV}+\mathrm{solar})$ & 15.50 & 14.30 & 15.06 & - \\
RISP [MWh] & 670 & 668 & 661 & 96.74 \\
FEUF (LHV) & 1.34 & 1.29 & 1.36 & 0.69 \\
FEUF (LHV + solar) & 0.80 & 0.79 & 0.80 & - \\
\hline
\end{tabular}

Despite the similar values of the yearly averaged input powers from fuel (which, in some cases, were even lower than the baseline case), the introduction of the solar field provided a substantial increase in the available thermal power for cogeneration purpose. In fact, the latter appears to be more than doubled, passing from the baseline case (mGT without solar field) to the hybrid plant regardless of the fuel considered.

$$
* \eta_{s o l}=\frac{P_{e l}}{\dot{m}_{f} * L H V+\dot{Q}_{s o l}},
$$

This occurrence is reflected in a dramatic improvement in the RISP index, which basically accounts for the energy saving associated with the unburnt fuel, achieved by means of the cogeneration unit. Moreover, it is worth mentioning that, in terms of RISP index, very similar performances are achieved by hydrogen and syngas fuels-slightly better than natural gas. Similar improvements are obtained for the Utilization Factor, FEUF-both fuel-only and fuel-solar based-thanks to the introduction of the solar field. However, the syngas case shows a slightly lower FEUF with respect to the other fuels because of a larger fuel input power. Nonetheless, the improvement with respect to the baseline case is still very large.

\subsection{Exergy Analysis}

In this section, an exergy analysis on the turbine exhaust gas flow rate was carried out to highlight the potential of mechanical energy available to the exchanger \#8 in the heat recovery unit, shown in Figure 1. As known, the exergy flow rate $\dot{\xi}$ of a fluid through a control volume can be written, neglecting kinetic and potential energies, as follows:

$$
\dot{\xi}=\dot{m}\left[\left(h_{8}-h_{9}\right)-T_{0}\left(s_{8}-s_{9}\right)\right],
$$

where $T_{0}$ is the reference state temperature, $h$ and $s$ are the specific enthalpy and entropy of the fluid at the specified state, and $h_{0}$ and $s_{0}$ are the corresponding properties at the dead state. Multiplying the specific flow exergy by the mass flow rate gives the exergy flow rate. Consequently, the second law efficiency $\eta_{I I}$ sol referred exclusively to fuel contribution is calculated as:

$$
\eta_{I I(\xi c h)}=\frac{P_{e l}+\dot{\xi}}{\dot{m}_{f} * \xi_{c h}}
$$

defining the solar input exergy flow as:

$$
\dot{\xi}_{s o l}=\dot{Q}_{s o l}\left(1-\frac{T_{0}}{T_{m}}\right),
$$


the second law efficiency $\eta_{I I}$ sol, accounting for both solar exergy input and fuel chemical exergy, can be defined as follows:

$$
\eta_{I I ~ s o l}=\frac{P_{e l}+\dot{\xi}}{\dot{m}_{f} * \xi_{c h}+\dot{\xi}_{s o l}} .
$$

In Table 7, yearly averaged values of exergy flow rate $\dot{\xi}$ and all second law parameters are reported for the three fuels calculated, along with those of the baseline case-i.e., mGT without solar field fueled by natural gas.

Table 7. Mean exergy flow rate in a year.

\begin{tabular}{ccccc}
\hline Fuel & Hydrogen & Syngas & Natural Gas & Baseline \\
\hline Chemical exergy $\xi \mathrm{ch}(\mathrm{kJ} / \mathrm{kg})$ & 117,600 & 7593 & 49,011 & 49,011 \\
Exergy flow rate $\dot{\xi}(\mathrm{kW})$ & 53.9 & 56.6 & 53.8 & 19.63 \\
Net Power Pel $(\mathrm{kW})$ & 27.52 & 26.67 & 26.89 & 28.14 \\
Fuel Exergy Input $(\mathrm{kW})$ & 103.2 & 117.1 & 109.9 & 122.29 \\
Input Solar Exergy $\dot{\xi}$ sol $(\mathrm{kW})$ & 38.32 & 37.23 & 38.22 & - \\
Second law efficiency $\eta I I s o l$ & 0.575 & 0.539 & 0.544 & - \\
Second law efficiency $\eta I I(\xi \mathrm{ch})$ & 0.788 & 0.711 & 0.734 & 0.391 \\
\hline
\end{tabular}

As one can see, regardless of the chosen fuel, the introduction of the solar field provides a large increase in the exergy flow rate available at the heat exchanger $\# 8$, with respect to the baseline case, which, in turn, provided a substantial increase in the second law efficiency. The last observation would eventually encourage further exploitation of the exergy content at heat exchanger \#8 for mechanical energy production via a bottoming cycle.

\section{CFD Analysis}

Beside carbon dioxide, it is important to take into account other pollutant species. Actually, relevant nitric oxides emissions represent an important issue for gas turbine operation. The high peak flame temperature and high oxygen concentration are the main causes of this harmful pollutant production.

A CFD based investigation can be extremely useful to check combustion effectiveness and pollutant formation. Simulations have been carried out by using FLUENT ${ }^{\circledR}$ flow solver. The reversed flow annular combustor was reproduced by a 2D mesh to reduce computational effort (Figure 18). In Figure 18, the features of the grid are listed, and a three-dimensional view of the combustor is displayed to better show its configuration.
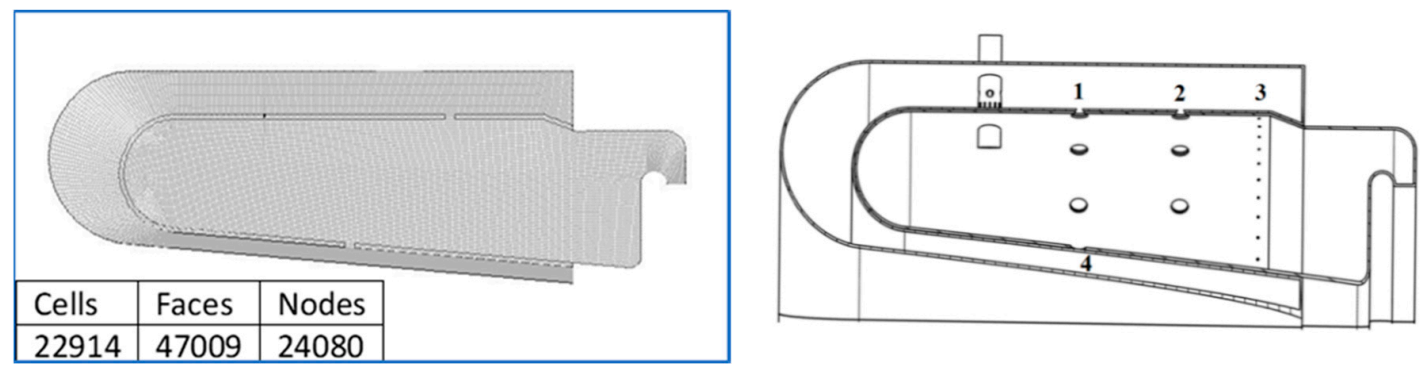

Figure 18. Combustor Mesh and $3 \mathrm{D}$ view of the $120^{\circ}$ sector of the combustor.

The chemical kinetics sub-model chosen for the combustion simulations is the well-established GRI-Mech 3.0, also tested by the authors in [10,27]. It consists of 53 species and 325 reactions and it includes detailed kinetics for methane, lighter hydrocarbons and hydrogen. A chain of reactions for the nitric oxide formation is also included. 
The combustion development is modelled by the Eddy dissipation concept (EDC), where the detailed Arrhenius chemical kinetics are incorporated in turbulent flames, and this make this model suitable to deal with simultaneous reactions.

Due to the high computational efforts required by calculations in order to deal with this complex kinetic mechanism, the heat transfer from the core to external liner was simulated by assigning a fixed temperature of $1000 \mathrm{~K}$ to the intermediate wall. Such a value was chosen based on previous simulations carried out on the same combustor by the authors, since this procedure allows a satisfactory evaluation of the temperature gradients within the primary region.

The CFD calculations use the boundary conditions shown in Table 8. The mass flow of each fuel is related to its LHV (Table 6): in order to reach the same TIT, the lower the LHV, the higher the amount of fuel introduced in the combustion chamber, as reported in Table 8.

Table 8. Boundary conditions.

\begin{tabular}{cccc}
\hline Fuel & Hydrogen & Syngas & Natural Gas \\
\hline Fuel mass flow rate $(\mathrm{kg} / \mathrm{s})$ & $9 \times 10^{-4}$ & $1.56 \times 10^{-2}$ & $2.3 \times 10^{-3}$ \\
Fuel temperature $\left({ }^{\circ} \mathrm{C}\right)$ & 25 & 25 & 25 \\
Injection pressure $(\mathrm{bar})$ & 5 & 5 & 5 \\
Air mass flow rate $(\mathrm{kg} / \mathrm{s})$ & 0.3056 & 0.3048 & 0.3056 \\
Air inlet Temperature $\left({ }^{\circ} \mathrm{C}\right)$ & 627 & 629 & 628 \\
Air inlet pressure $(\mathrm{bar})$ & 3.472 & 3.567 & 3.469 \\
\hline
\end{tabular}

It is important to highlight that the air mass flow rate reported in Table 8 is actually split into two parts. The main one is assigned to the inlet from the recuperator. This air crosses the external liner and is progressively introduced in the internal liner for the completion of oxidation and gas dilution.

As a matter of fact, the injector also crosses the external liner and faces directly in the primary zone (Figure 18); a small amount of the air coming from the recuperator is trapped in the injector through holes that are properly oriented to provide a swirl motion to the air that is mixed with the fuel inside the injector. In this way, a premixed mixture is formed and burns in the primary zone of the internal liner. However, the difficulties encountered in the simulation of this configuration in a 2D domain suggested to the authors to split the total mass flow rate and to assign a fixed direct injection of air from the fuel inlet for each fuel.

In Table 9, the results, in terms of temperatures and emissions, are listed. As already stated, the characteristics reported in Table 1 were used for the calculations in the zero-dimensional solver. In particular, the fuel mass flow was calculated in order to reach a TIT (or combustor outlet temperature) of $1173 \mathrm{~K}$. The amount of each fuel is different since the three fuels have different LHV, and this could lead to a different combustion development. However, the target temperature at the outlet is reached for all cases. Moreover, as expected, the higher temperature peak in the combustor are attained in the case with hydrogen since it has the higher adiabatic flame temperature. The lower temperature obtained by the syngas combustion leads to an effective reduction in nitric oxides at the outlet with respect to the other two fuels. Additionally, in Table 9 the concentrations of the main species for each fuel, respectively, $\mathrm{H}_{2}, \mathrm{CO}$ and $\mathrm{CH}_{4}$, as reported in Table 2, are compared. As it is noted, hydrogen and natural gas present an efficient combustion while the syngas case shows that a significant amount of carbon monoxide is not able to be converted in $\mathrm{CO}_{2}$. A possible cause can be found in the evaluation of the fuel and air mass flow rates in Table 8. Indeed, to achieve the same TIT, a higher amount of syngas must be introduced, while a lower air flow is necessary to keep the same operating conditions of the micro gas turbine. Therefore, the air amount decrease prevents the complete oxidation of the fuel. Finally, it is important to evidence that the use of hydrogen does not produce emissions of $\mathrm{CO}_{2}$ and $\mathrm{CO}$ at the outlet. 
Table 9. Output.

\begin{tabular}{cccc}
\hline Fuel & Hydrogen & Syngas & Natural Gas \\
\hline $\mathrm{T}_{\text {out }}(\mathrm{K})$ & 1146.6 & 1194.7 & 1219.3 \\
$\mathrm{~T}_{\text {max }}(\mathrm{K})$ & 2653.8 & 2286.9 & 2568.5 \\
$\mathrm{NO}_{\mathrm{x}}(\mathrm{ppm})$ & 126 & 20.62 & 126 \\
$\mathrm{Main}$ fuel $(\mathrm{ppm})$ & $\left(\mathrm{H}_{2}\right) 9.6 \times 10^{-2}$ & $(\mathrm{CO}) 180$ & $\left(\mathrm{CH}_{4}\right) 2.26 \times 10^{-7}$ \\
$\mathrm{CO}_{2}(\mathrm{ppm})$ & - & 42,984 & 23,488 \\
$\mathrm{CO}(\mathrm{ppm})$ & - & 180 & 69.4 \\
\hline
\end{tabular}

In Figure 19, temperature distributions show higher peaks for the case with hydrogen, as already highlighted in Table 9. However, this case presents the same emissions of $\mathrm{NO}_{\mathrm{x}}$ as the natural gas case. Indeed, despite NG does not achieve the same maximum temperature as hydrogen, the wider extension of the zone promotes the nitric oxides formation. This is confirmed by the NO distribution in Figure 20 and its reaction rate in Figure 21, as the higher concentrations and rates of reaction are detected in correspondence with the higher temperatures.

In Figure 22, the distributions of $\mathrm{OH}$ are illustrated because this radical is an important intermediate species of the hydrocarbons chain of reactions, this means that the highest concentrations of this species identify the location of combustion activity. As it is possible to notice in all cases, the combustion is delimited in the primary and secondary zones, that are characterized by the most significant $\mathrm{OH}$ presence. A reduced $\mathrm{OH}$ concentration is also observed after the last row of dilution holes, especially in the syngas and Natural Gas cases, thus indicating that the completion of the oxidation process involves the dilution zone.

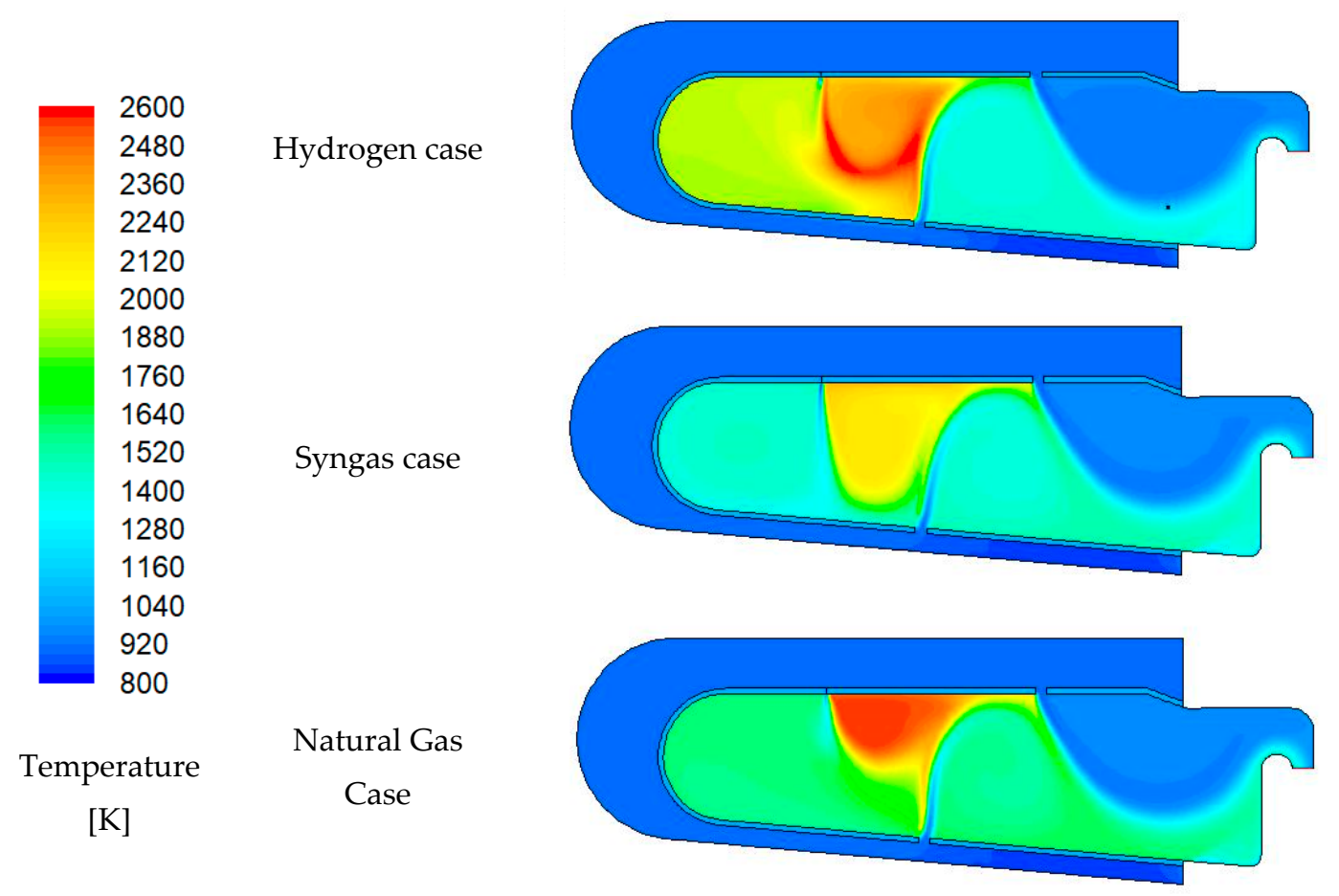

Figure 19. Temperature distributions in combustor. 


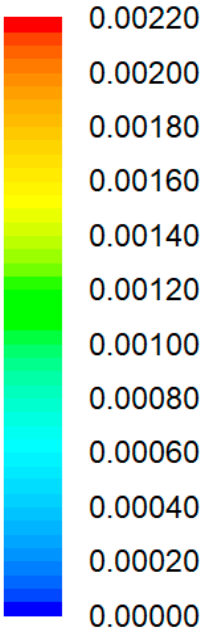

NO mass fraction
Hydrogen case
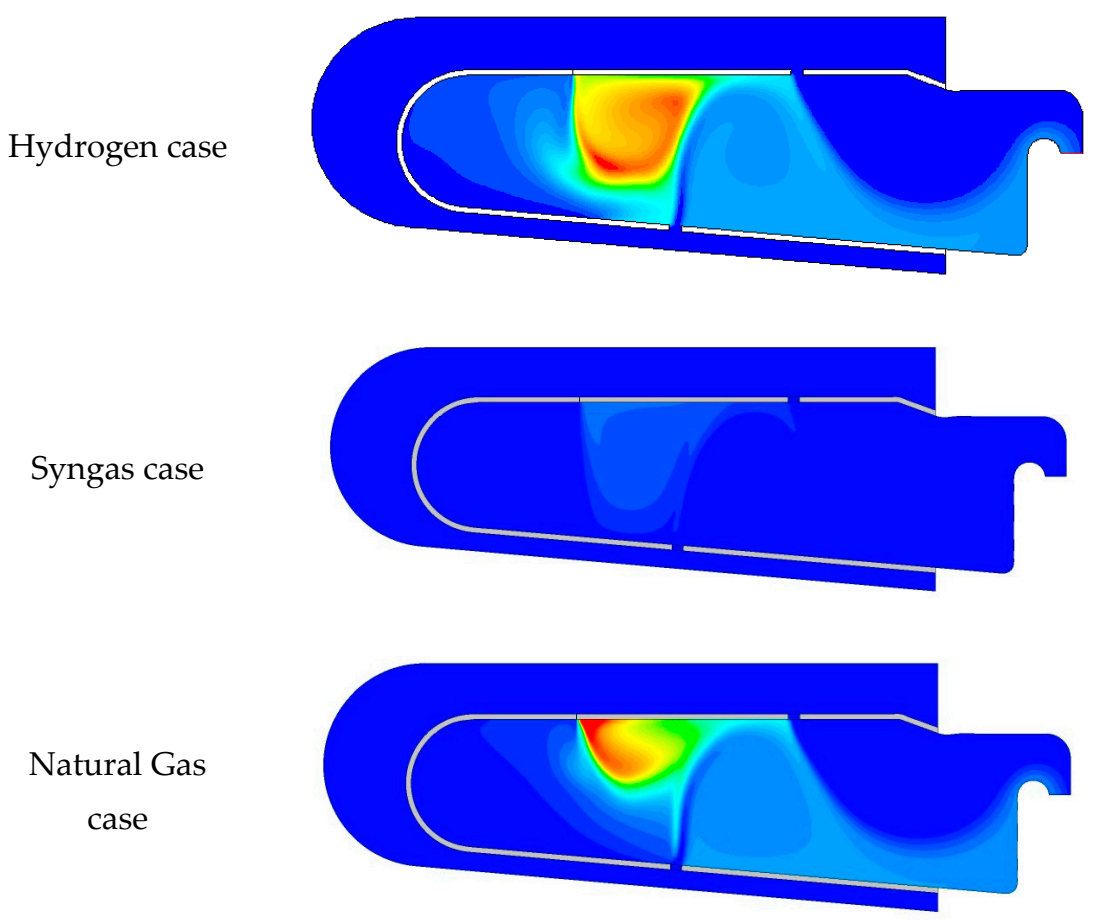

Figure 20. NO distributions in combustor.

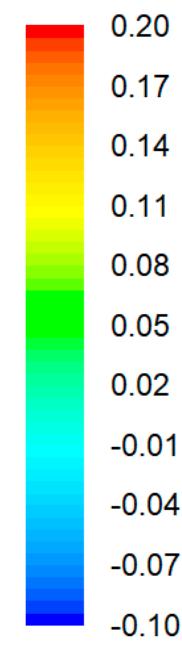

Net Reaction rate of $\mathrm{NO}$ $\left[\mathrm{kg} / \mathrm{m}^{3} \mathrm{~s}\right]$

\section{Hydrogen case}
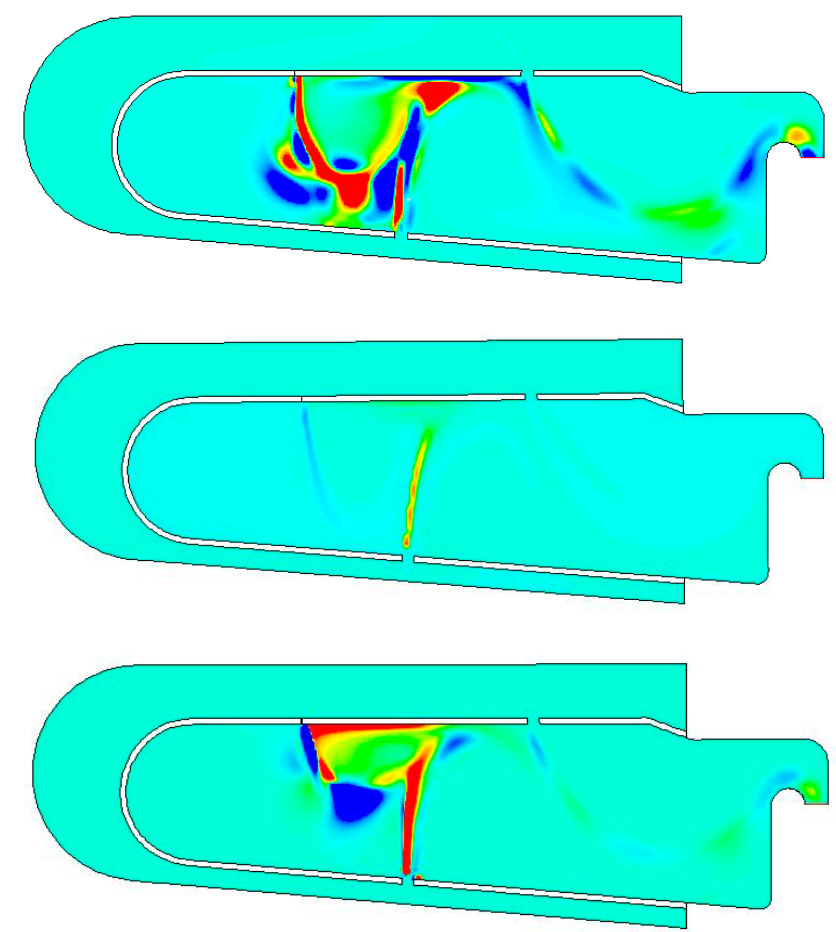

Figure 21. Net Reaction rate of NO distributions in combustor. 


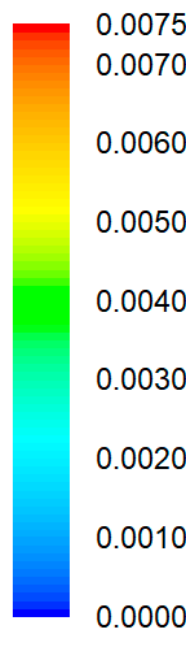

OH Mass

Faction
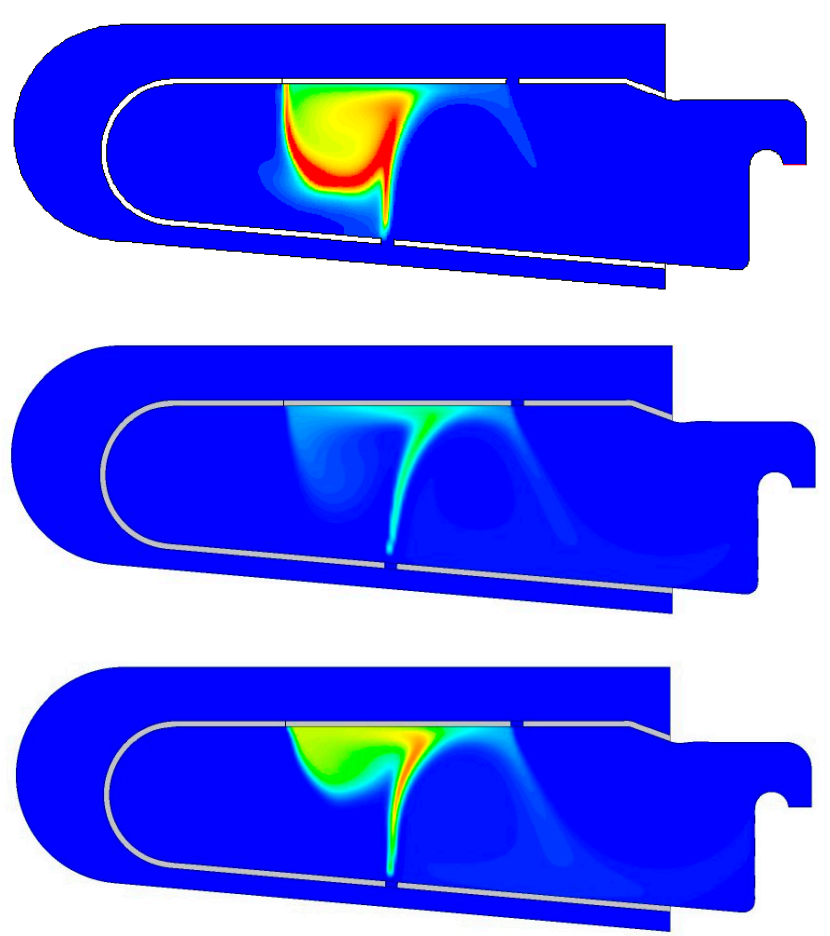

Figure 22. $\mathrm{OH}$ distributions in combustor.

Finally, in Figures 23 and 24, the reaction rate of the main species for each fuel and the related mass fractions are displayed. Indeed, as already demonstrated by the authors $[7,10,27]$, the combustor behavior approaches that typical of an RQL combustor. Hence, the fuel distribution is promoted by the swirl motion generated inside the combustor, which does not vary with the fuel used and has the aim to form in a primary zone a rich mixture with a poor availability of oxygen in order to prevent the nitric oxides formation. However, in the syngas case this behavior is accentuated by the increased amount of fuel introduced. The rich mixture is even farther away from the stoichiometric value and, different from $\mathrm{H}_{2}$ and $\mathrm{CH}_{4}$ that start to burn near the injector, the main oxidation occurs only in proximity of the first row of dilution holes, as evidenced in Figure 23. This could explain the higher concentration of $\mathrm{CO}$ in the secondary zone, the slower combustion of syngas and the reduced amount of $\mathrm{NO}_{\mathrm{x}}$ at the outlet.

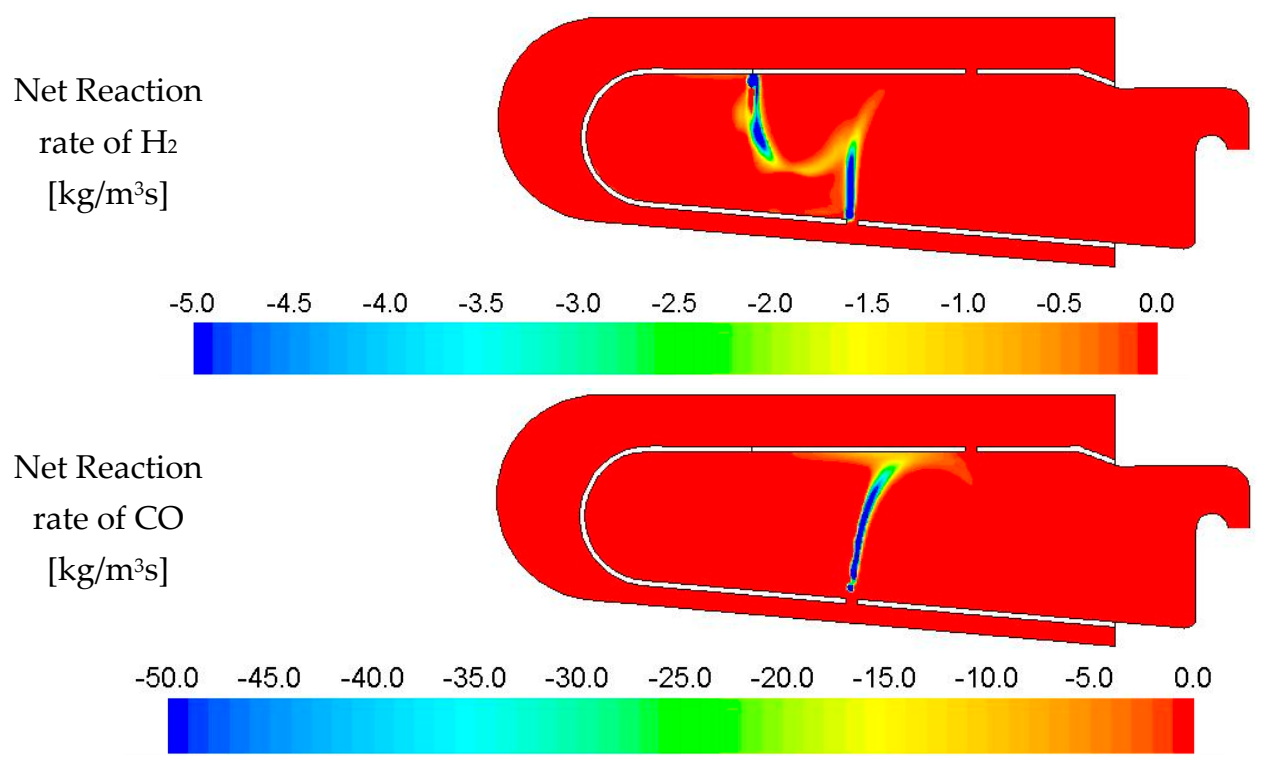

Figure 23. Cont. 


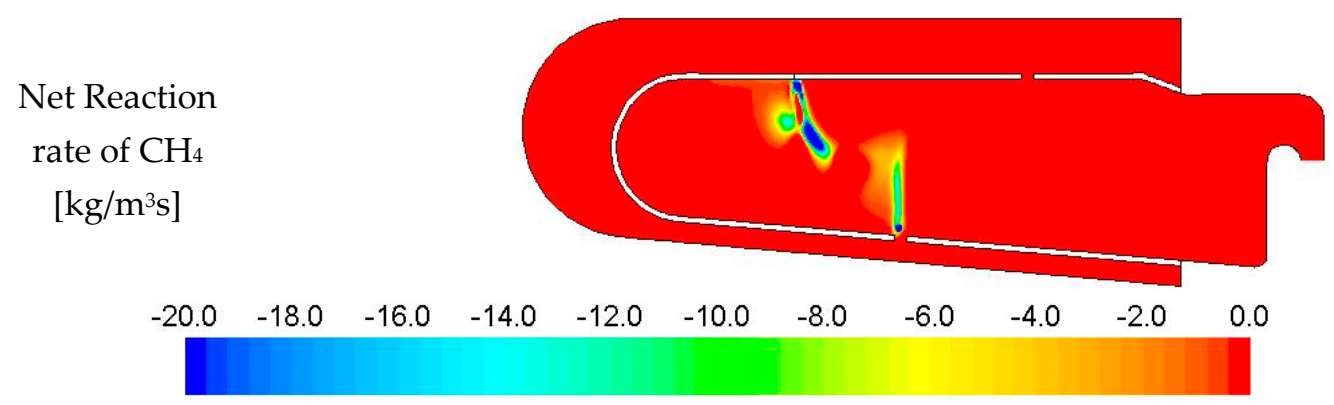

Figure 23. Mass fractions distributions of the main species for each fuel.

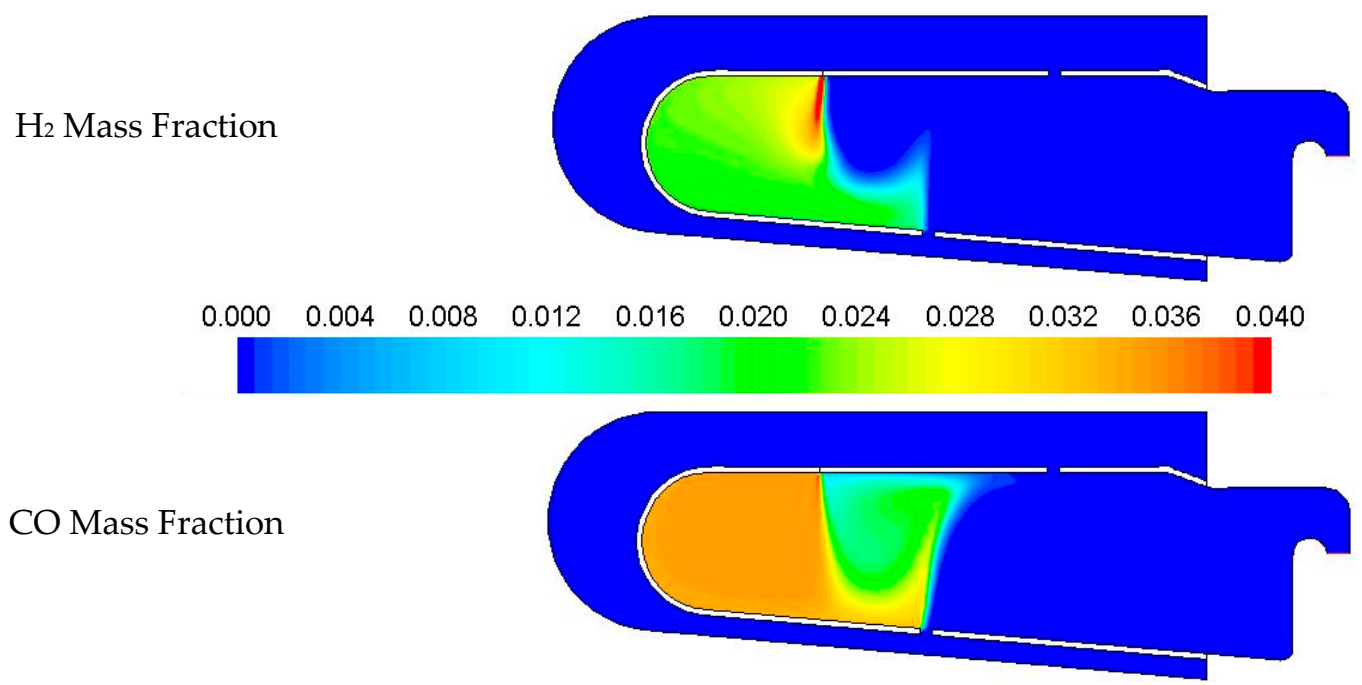

$\begin{array}{llllllllllllllll}0.00 & 0.01 & 0.02 & 0.03 & 0.04 & 0.05 & 0.06 & 0.07 & 0.08 & 0.09 & 0.10 & 0.11 & 0.12 & 0.13 & 0.14 & 0.15\end{array}$

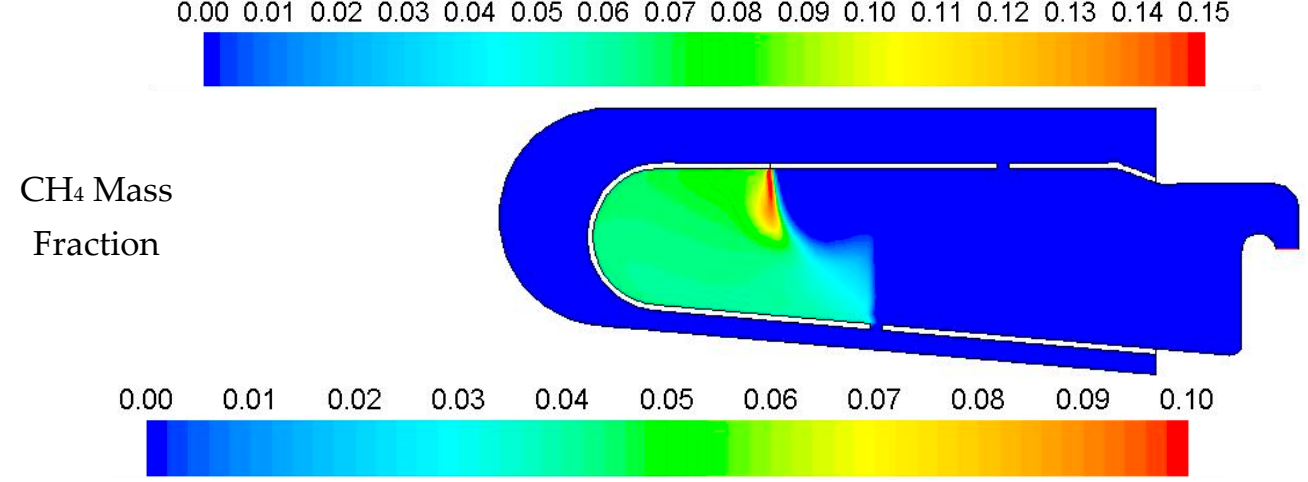

Figure 24. Mass fraction distributions of the main species for each fuel.

As illustrated in Figure 24, despite the different scales used for the distinct fuels, in all cases the primary zone is characterized by high concentration of fuel while the mixing with air and then the main oxidation process occurs between the primary and secondary zone.

\section{Conclusions}

The present work showed a thermodynamic analysis carried out on a mGT-based power plant with solar field and thermal storage, provided with a Heat Recovery Unit for cogeneration purpose. The analysis was first carried out for a given day with and without thermal storage to assess its beneficial impact on fuel demand during night hours. Subsequently, the analysis was extended to the assessment of the plant response to two alternative fuels-i.e., pure hydrogen and syngas from agriculture waste, namely olive pits, which were compared against the natural gas case. Calculations were first performed on an hour-to-hour basis for a single day, and were later, extended to 12 months. 
To assess the relative performance of the three fuels, several figures of merit were considered-e.g., net power output, fuel-based thermal efficiency, thermal power to the $\mathrm{HRU}$ and specific $\mathrm{CO}_{2}$ emission. Additionally, to enhance the legibility of the impact of thermal storage on energy availability and fuel demand during night hours, two groups of results were presented-i.e., daylight and night hour average quantities.

Concerning fuel response analysis, from a specific $\mathrm{CO}_{2}$ emissions point of view, pure hydrogen was obviously the best alternative with basically negligible values, whereas syngas was shown to produce the largest amount of $\mathrm{CO}_{2}$ per $\mathrm{kWh}$. Nevertheless, it is to be kept in mind that syngas, being a fuel from vegetable origin, is considered neutral by legislation. Furthermore, pure hydrogen fuel proved to be the best solution from power and efficiency point of view, both for single day and 12 months analyses. Conversely, syngas stood out from heat transferred to the HRU point of view, both for single day and 12 months analyses.

Subsequently, in view of the large amount of thermal energy available to the HRU, a detailed analysis of the cogeneration process as well as an exergy analysis were performed. Results showed that the adoption of the solar field led to a substantial increase in the thermal power available to the HRU, independently of the fuel considered, which, in turn, largely increased RISP index and FEUF, with the best results achieved by syngas and hydrogen. Likewise, exergy analysis proved that the introduction of the solar field almost doubled the exergy flow rate availability at HRU, with a large improvement in second law efficiency.

Finally, a CFD analysis carried out using the well-established GRI-Mech 3.0 on the FLUENT ${ }^{\circledR}$ flow solver demonstrated that, as expected, the higher temperature peak in the combustor are attained in the case with hydrogen since it has the higher adiabatic flame temperature, presenting the same emissions of $\mathrm{NO}_{x}$ as the natural gas case, since this last case is characterized by wider extensions of the zones at high temperature that promote the nitric oxides formation. On the contrary, the lower temperature obtained by the syngas combustion leads to an effective reduction in nitric oxides at the outlet with respect to the other two fuels. However, the syngas case shows that a significant amount of carbon monoxide is not able to be converted in $\mathrm{CO}_{2}$, different from hydrogen and natural gas, that present an efficient combustion; in particular the use of hydrogen does not produce emissions of $\mathrm{CO}_{2}$ and $\mathrm{CO}$ at the outlet.

Author Contributions: Conceptualization, methodology, software, validation, formal analysis, writing-original draft preparation, writing - review and editing, M.C.C., A.C., R.D.R. and R.T. All authors have read and agreed to the published version of the manuscript.

Funding: This research received no external funding.

Acknowledgments: The plant simulations are performed by the THERMOFLEX software, licensed from Thermoflow Inc. The CFD computations are licensed by ANSYS-FLUENT.

Conflicts of Interest: The authors declare no conflict of interest.

\section{References}

1. Cameretti, M.C. Modelling of a Hybrid Solar Micro-Gas Turbine fuelled by biomass from agriculture product. Energy Rep. 2020, 6, 105-116. [CrossRef]

2. Singh, A.; Baredar, P. Techno-economic assessment of a solar PV, fuel cell, and biomass gasifier hybrid energy system. Energy Rep. 2016, 2, 254-260. [CrossRef]

3. Abagnale, C.; Cameretti, M.C.; De Robbio, R.; Tuccillo, R. Thermal cycle and Combustion Analysis of a Solar-assisted Micro Gas Turbine. Energies 2017, 10, 773. [CrossRef]

4. Cameretti, M.C.; De Robbio, R.; Pirone, E.; Tuccillo, R. Thermo-Economic Analysis of a Hybrid Solar Micro Gas Turbine Power Plant. Energy Procedia 2017, 126, 667-674. [CrossRef]

5. Cameretti, M.C.; Langella, G.; Sabino, S.; Tuccillo, R. Modeling of A Hybrid Solar Micro Gas-Turbine Power Plant. Energy Procedia 2015, 62, 833-840. [CrossRef]

6. Taylan, O.; Berberoglu, H. Fuel product using concentrated solar energy. In Application of Solar Energy; Intech: Rijeka, Croatia, 2013; pp. 33-67. [CrossRef] 
7. Abagnale, C.; Cameretti, M.C.; De Robbio, R.; Tuccillo, R. CFD Study of a Micro Gas Turbine Supplied with Syngas. Energy Procedia 2016, 101, 933-940. [CrossRef]

8. Cameretti, M.C.; Tuccillo, R.; Piazzesi, R. Study of an exhaust gas recirculation equipped micro gas turbine supplied with bio-fuels. Appl. Therm. Eng. 2013, 59, 162-173. [CrossRef]

9. Cameretti, M.C.; Tuccillo, R. Combustion Features of a Bio-Fuelled Micro-Gas Turbine. Appl. Therm. Eng. 2015, 89, 280-290. [CrossRef]

10. Cameretti, M.C.; De Robbio, R.; Tuccillo, R.; Reale, F.; Chiariello, F. Methane-Hydrogen Blends in Micro Gas Turbines: Comparison of Different Combustor Concepts, ASME paper GT2019-90229. In Proceedings of the ASME Turbo Expo 2019: Turbomachinery Technical Conference and Exposition GT2019, Phoenix, AZ, USA, 17-21 June 2019.

11. Meziane, S.; Bentebbiche, A. Numerical study of blended fuel natural gas-hydrogen combustion in rich/quench/lean combustor of a micro gas turbine. Int. J. Hydrogen Energy 2019, 44, 15610-15621. [CrossRef]

12. Abd El-Sattar, H.; Kamel, S.; Tawfik, M.A.; Vera, D.; Jurado, F. Modeling and Simulation of Corn Stover Gasifier and Micro-turbine for Power Generation. Waste Biomass Valor. 2019, 10, 3101-3114. [CrossRef]

13. Mărculescu, C.; Cenuşă, V.E.; Alexe, F.N. Analysis on using biomass lean syngas in micro gas turbines. Earth Environ. Sci. 2016, 40, 012036. [CrossRef]

14. Nicolosi, F.F.; Renzi, M. Effect of the Regenerator Efficiency on the Performance of a Micro Gas Turbine Fed with Alternative Fuels. Energy Procedia 2018, 148, 687-694. [CrossRef]

15. Hasini, H.; Fadhil, S.S.A.; Mat Zian, N.; Om, N.I. CFD Investigation of Pollutant Emission in Can-Type Combustor Firing Natural Gas, LNG and Syngas. Earth Environ. Sci. 2016, 32, 012073. [CrossRef]

16. Ammar, N.R.; Farag, A.I. CFD Modeling of Syngas Combustion and Emissions for Marine Gas Turbine Applications. Pol. Marit. Res. 2016, 23, 39-49. [CrossRef]

17. Kéromnès, A.; Metcalfe, W.K.; Heufer, K.A.; Donohoe, N.; Das, A.K.; Sung, C.; Herzler, J.; Naumann, C.; Griebel, P.; Mathieu, O.; et al. An experimental and detailed chemical kinetic modeling study of hydrogen and syngas mixture oxidation at elevated pressures. Combust. Flame 2013, 160, 995-1011. [CrossRef]

18. Fareeza, N.; Tan, E.S.; Kumaran, P.; Indra, T.M.; Fadzilah, N.; Yoshikawa, K. Evaluating the Effect of Syngas Composition on Micro gas turbine Performance. Earth Environ. Sci. 2016, 32, 012042. [CrossRef]

19. Othman, N.F.; Boosroh, M.H. Effect of $\mathrm{H} 2$ and $\mathrm{CO}$ contents in syngas during combustion using Micro Gas Turbine. Earth Environ. Sci. 2016, 32, 012037. [CrossRef]

20. Pambudi, N.A.; Itaoka, K.; Kurosawa, A.; Yamakawa, N. Impact of hydrogen fuel for CO2 emission reduction in power generation sector in Japan. Energy Procedia 2017, 105, 3075-3082. [CrossRef]

21. Devriese, C.; Pennings, W.; de Reuver, H.; Bastiaans, R.; De Paepe, W. The preliminary CFD design of a compressor and combustor system towards a $100 \mathrm{~kW}$ hydrogen fuelled micro gas turbine. In Proceedings of the ASME Turbo Expo2019, Phoenix, AZ, USA, 17-21 June 2019.

22. Renzi, M.; Riolfi, C.; Baratieri, M. Influence of the syngas feed on the combustion process and performance of a micro gas turbine with steam injection. Energy Procedia 2017, 105, 1665-1670. [CrossRef]

23. Borello, D.; Pantaleo, A.M.; Caucci, M.; De Caprariis, B.; De Filippis, P.; Shah, N. Modeling and Experimental Study of a Small Scale Olive Pomace Gasifier for Cogeneration: Energy and Profitability Analysis. Energies 2017, 10, 1930. [CrossRef]

24. Allesina, G.; Pedrazzi, S.; Allegretti, F.; Morselli, N.; Puglia, M.; Santunione, G.; Tartarini, P. Gasification of cotton crop residues for combined power and biochar production in Mozambique. Int. J. Hydrogen Energy 2018, 43, 14214-14225. [CrossRef]

25. Hwang, I.H.; Kobayashi, J.; Kawamoto, K. Characterization of products obtained from pyrolysis and steam gasification of wood waste, RDF, and RPF. Waste Manag. 2014, 34, 402-410. [CrossRef] [PubMed]

26. Yulianto, M.; Agustina, S.E.; Hartulistiyoso, E.; Nelwan, L.O.; Nurlela. Study of temperature characterization of agricultural waste in the development of stove for combine heat power. AIP Conf. Proc. 2017, 1826, 020031. [CrossRef]

27. De Robbio, R. Innovative combustion analysis of a micro-gas turbine burner supplied with hydrogen-natural gas mixtures. Energy Procedia 2017, 126, 858-866. [CrossRef] 
28. Cameretti, M.C.; De Robbio, R.; Tuccillo, R. CFD study of a micro-combustor under variable operating conditions. In Proceedings of the ASME Turbo Expo 2017: Turbomachinery Technical Conference and Exposition, Charlotter, NC, USA, 26-30 June 2017.

29. Available online: www.eurometeo.com (accessed on 27 February 2020).

(C) 2020 by the authors. Licensee MDPI, Basel, Switzerland. This article is an open access article distributed under the terms and conditions of the Creative Commons Attribution (CC BY) license (http://creativecommons.org/licenses/by/4.0/). 